\title{
A blackbox optimization of volumetric heating rate for reducing the wetness of the steam flow through turbine blades
}

\author{
Davood Hoseinzade ${ }^{a}$, Esmail Lakzian ${ }^{a, *}$, Ali Hashemian ${ }^{b, c}$ \\ ${ }^{a}$ Center of Computational Energy, Department of Mechanical Engineering, Hakim Sabzevari University, Sabzevar, Iran \\ ${ }^{b}$ BCAM - Basque Center for Applied Mathematics, Bilbao, Basque Country, Spain \\ ${ }^{c}$ Department of Mechanical Engineering, Hakim Sabzevari University, Sabzevar, Iran
}

\section{ARTICLE INFO}

\section{Keywords:}

Multiobjective blackbox optimization

Wet steam flow

Volumetric heating rate

Steam turbines

\begin{abstract}
A B S T R ACT
This paper proposes to use a blackbox optimization to obtain the optimal volumetric heating required to reduce the wetness at the last stages of steam turbines. For this purpose, a global multiobjective optimization is utilized through the automatic linking of genetic algorithm and CFD code, where the blackbox function evaluations are performed by CFD runs. The logarithm of number of droplets per volume (LND), the droplet average radius (DAR), and the integral of local entropy (ILE) at the end of the cascade (after the condensation location) are minimized, while the volumetric heating rate is the optimization parameter. The Eulerian-Eulerian approach is implemented to model the two-phase wet steam turbulent flow and the numerical results are validated against well-established experiments. Since higher volumetric heating rates reduce DAR and LND, while increase ILE, according to optimization results, there is an optimum for the volumetric heating rate to reach the best performance of steam turbines. For case studies presented in this work, the optimal volumetric heating rates of $5.21 \times 10^{8}$ and $4.67 \times 10^{8} \mathrm{~W} / \mathrm{m}^{2}$ are obtained for two different cases of supersonic and subsonic outlets, respectively. Particularly, these rates improve DAR by $45.7 \%$ and $57.5 \%$, and LND by $6.0 \%$ and $7.8 \%$ for respective cases.
\end{abstract}

\section{Introduction}

The expansion of steam flow at the last stages of steam turbines brings in the non-equilibrium state of the flow. Consequently, a two-phase flow is formed, where the droplets are typically known as one of the major sources of thermodynamic and mechanical losses. Throughout the literature, there exist a plethora of researches attempting to identify and reduce these losses in steam turbines with investigations on the classical nucleation theory of droplets. Bakhtar et al. [1] discussed the classical theory of the homogeneous nucleation of droplets and its application in predicting condensation in steam nozzles. They described the treatment of twodimensional nucleating steam flows using two different timemarching numerical schemes. Xu and Yuan [2] proposed an online applicable approach based on equivalent overall efficiency models to monitor the exhaust steam wetness fraction. Wróblewski and Dykas [3] used the method of moments to reconstruct of the water droplet size distribution and model the liquid phase evolution in the flow through the de Laval nozzle. Tang et al. [4] presented a visualization experimental study of the condensing flow regime in the transonic mixing process of steam ejectors. Sinha et al. [5] and Hagmeijer et al. [6] presented models of droplet growth, based on the kinetic theory of gases which is referred to as the Hertz-Knudsen relationship. Dykas et al. [7] conducted an experimental study of condensation flow in a nozzle, providing accurate experimental data for the homogeneous nu-

\footnotetext{
${ }^{*}$ Corresponding author (Tel.: +98 5144012818 )

e.lakzianehsu.ac.ir (E. Lakzian)
}

cleation, which is widely used to validate the numerical results in nozzles. Other studies on the non-equilibrium condensation flow inside nozzles can be found in the works of, e.g., Dykas and Wróblewski [8] that presented a two-fluid model for solving the governing equations of viscous vapor and inviscid liquid phases, Patel et al. [9] that included turbulence models in the nucleation and droplets growth phenomena, and Senguttuvan and Lee [10] that considered the effect of different nozzles' geometries.

Bakhtar and Zidi experimentally [11] and theoretically [12] studied the condensation steam flows in a steam turbine to analyze the axial pressure distribution on the suction and pressure sides of the blade, and also to measure the droplet average radius. The results, which are considered as a well-known reference in many other researches, showed that the theoretical pressure distribution are in agreements with the experimental results, whereas the droplet radius prediction that is less consistent with the experimental data. Yousif et al. [13] numerically and experimentally investigated homogeneous non-equilibrium condensation in a transonic steam flow at a low-pressure turbine cascade. Their numerical results showed that in the case of the transonic flow, the condensation zone occurs downstream of the throat and is not accompanied by an increase in the pressure, whereas in the experimental results there was no evidence of this condensation. Gerber and Kermani [14] used a multiphase Eulerian-Eulerian pressure-based model for transonic turbulent steam flow, with the application in investigating large multi-stage turbines in which the wetness arises under non-equilibrium conditions. Nikkhahi et al. [15] inves- 


\begin{tabular}{|c|c|c|c|}
\hline \multicolumn{4}{|c|}{ Nomenclature } \\
\hline$A$ & Area $\left(\mathrm{m}^{2}\right)$ & $T$ & Temperature $(\mathrm{K})$ \\
\hline$a_{i}$ & Constants of entropy equation $\left.(\mathrm{kJ} / \mathrm{kg} \mathrm{K})^{i}\right)$ & $T_{D}$ & Reference temperature $(\mathrm{K})$ \\
\hline$B_{2}$ & Second virial coefficient $\left(\mathrm{m}^{3} / \mathrm{kg}\right)$ & $t$ & Time (s) \\
\hline$B_{3}$ & third virial coefficient $\left(\mathrm{m}^{6} / \mathrm{kg}^{2}\right)$ & $u$ & Velocity $(\mathrm{m} / \mathrm{s})$ \\
\hline$b_{1}, b_{2}, b_{3}$ & Constants of equation of state $\left(\mathrm{m}^{3} / \mathrm{kg}\right)$ & $V_{d}$ & Average volume of droplets $\left(\mathrm{m}^{3}\right)$ \\
\hline$b_{4}, b_{5}$ & Constants of equation of state $\left(\mathrm{m}^{6} / \mathrm{kg}^{2}\right)$ & $w$ & Mass fraction (-) \\
\hline$C_{l}$ & Specific heat of liquid $(\mathrm{J} / \mathrm{kg} \mathrm{K})$ & $X$ & Length parameter of blade cascade $(\mathrm{m})$ \\
\hline$C_{p}$ & Specific heat at constant pressure $(\mathrm{J} / \mathrm{kg} \mathrm{K})$ & $x$ & Coordinate $(\mathrm{m})$ \\
\hline$C_{v}$ & Specific heat at constant volume $(\mathrm{J} / \mathrm{kg} \mathrm{K})$ & $(-)$ & Dimensionless symbol \\
\hline DAR & Droplet average radius $(\mu \mathrm{m})$ & & \\
\hline$G$ & Gibbs free energy $(\mathrm{J} / \mathrm{kg})$ & \multicolumn{2}{|c|}{ Greek letters } \\
\hline$H$ & Total enthalpy (J/kg) & $\alpha_{1}$ & Constant of equation of state $(\mathrm{K})$ \\
\hline$h$ & Enthalpy $(\mathrm{J} / \mathrm{kg})$ & $\alpha_{2}$ & Constant of equation of state (-) \\
\hline$I$ & Droplet nucleation rate $\left(1 / \mathrm{m}^{3} \mathrm{~s}\right)$ & $\beta$ & Liquid mass fraction (-) \\
\hline ILE & Integral of local entropy $(\mathrm{W} / \mathrm{K})$ & $\Gamma$ & Mass generation rate $\left(\mathrm{kg} / \mathrm{m}^{3} \mathrm{~s}\right)$ \\
\hline$K_{b}$ & Boltzmann constant $(\mathrm{J} / \mathrm{K})$ & $\eta$ & Number of droplets per volume $\left(1 / \mathrm{m}^{3}\right)$ \\
\hline$K_{t}$ & Conduction coefficient $(\mathrm{W} / \mathrm{m} \mathrm{K})$ & $\theta$ & Non-isothermal correction factor $(-)$ \\
\hline$k$ & Turbulence kinetic energy $\left(\mathrm{m}^{2} / \mathrm{s}^{2}\right)$ & $\rho$ & Density $\left(\mathrm{kg} / \mathrm{m}^{3}\right)$ \\
\hline$L$ & Total length of blade cascade (m) & $\sigma_{r}$ & Liquid surface tension $(\mathrm{N} / \mathrm{m})$ \\
\hline LND & $\log _{10}($ Number of droplets per volume $)\left(1 / \mathrm{m}^{3}\right)$ & $\tau$ & Viscous stress tensor $(\mathrm{Pa})$ \\
\hline$M_{a}$ & Mach number (-) & $\tau_{0}, \tau_{1}, \tau_{2}$ & Constants of equation of state (-) \\
\hline$M_{m}$ & Molecular mass $(\mathrm{kg} / \mathrm{mol})$ & $\phi$ & Properties of mixture (-) \\
\hline$m_{r}$ & Liquid mass (kg) & $\omega$ & Specific rate of dissipation $(1 / \mathrm{s})$ \\
\hline$P$ & Pressure $(\mathrm{Pa})$ & & \\
\hline$Q$ & Volumetric heating rate $\left(\mathrm{W} / \mathrm{m}^{2}\right)$ & \multicolumn{2}{|c|}{ Subscripts and superscripts } \\
\hline$q$ & Heat flux $\left(\mathrm{W} / \mathrm{m}^{2}\right)$ & $d$ & Droplet \\
\hline$R$ & Gas constant $(\mathrm{J} / \mathrm{kg} \mathrm{K})$ & $l$ & Liquid \\
\hline$r$ & Droplet radius (m) & $\operatorname{mix}$ & Mixture (liquid-vapor) \\
\hline $\bar{r}$ & Average radius (m) & out & Outlet flow \\
\hline$S$ & Supersaturation ratio (-) & sat & Saturate \\
\hline$s$ & Entropy $(\mathrm{J} / \mathrm{kg} \mathrm{K})$ & $v$ & Vapor \\
\hline$s_{c}$ & Constant of entropy equation $(\mathrm{J} / \mathrm{kg} \mathrm{K})$ & $*$ & Critical \\
\hline
\end{tabular}

tigated the effect of back-pressure change on the two-phase in the two-dimensional model of turbine cascade using the Eulerian-Eulerian approach. Their results showed that the highest condensation occurs on the suction walls and is reduced by with decreasing the downstream pressure.

The importance of volumetric heating in reducing the performance losses of steam turbines is studied in recent years. Mahpeykar et al. [16] applied volumetric heating to the convergence part of a one-dimensional convergentdiverging nozzle and studied the steam condensation flow parameters as well as the entropy generation. They observed that by adding appropriate volumetric heating, the nucleation rate and supercooling temperature could be significantly reduced. Amiri Rad et al. [17] analytically analyzed the effect of the static inlet pressure and the volumetric heating on the two-phase supersonic flow in a one-dimensional convergent-divergent nozzle. Aliabadi et al. [18] studied the injection of hot steam into the wet flow at the inlet of the turbine cascade. Their results indicated that the hot steam injection reduces the erosion rate and condensation losses due to the reduction of droplets. In addition, they showed that changing the position of injection can reduce the affects of pressure changes, wetness fraction, and Mach number on the pressure and suction walls, implying that there is an opti- mal location for the hot steam injection. In another research, Vatanmakan et al. [19] numerically investigated the effect of different volumetric heating rates on the entropy generation and wetness fraction. They showed that the wetness fraction is decreased by increasing the volumetric heating, while the entropy generation first reveals a decreasing trend followed by an increasing pattern. Hosseini and Lakzian [20] also added volumetric heating to the fluid flow in the convergent part of the turbine. Their results showed that by increasing the volumetric heating rate, the wetness fraction and economic cost of power generation are changed. Based on their results, there is an optimal volumetric heating that minimizes the wetness and, hence, the economic cost. Other investigated factors in reducing the thermodynamic loss of steam turbines are, e.g., the surface roughness of blades [21], employing different divergence angle [22], droplet spraying [23], different rates of expansion and injection of water droplets [24], and existence of wetness at inlet [25].

The application of optimization techniques, particularly in the sense of genetic algorithm (GA) [26], in wet steam flow simulation is also of interest. Keisari and Shams [27] used a multiobjective GA to find an optimal geometry for the nozzle. The objectives of this optimization were the droplet radius and wetness fraction. Mirhoseini and Boroomand [28] 
used GA to find the optimal hot steam rate to reduce the wetness in nozzles, considering that adding the hot steam to wet flow reduces the wetness fraction. Rahim Abadi et al. [29] utilized the GA technique to obtain an optimal geometry for 3D nozzles and 2D turbine blades in order to reduce the wetness at the end of the passage by considering the droplet nucleation rate and maximum droplet radius as the most important factors. Trigg et al. [30] also presented an automated GA to find an optimal geometry for turbine blades, considering different characteristics of the flow as objectives.

This paper proposes to apply an optimal rate of volumetric heating to the convergent section of the stationary blade cascades to reduce the losses at the last stages of steam turbines. To achieve this, it is proposed to minimize the logarithm of number of droplet per volume (LND), the droplet average radius (DAR), and the integral of local entropy (ILE), all measured at the end of the blade cascade, in a multiobjective optimization. Herein, the volumetric heating rate is considered as the design variable. For this purpose, a blackbox optimization procedure through the automatic linking of the GA algorithm and the CFD code is utilized, in which the function evaluations are performed by means of CFD runs. Here, blackbox refers to the problems for which a close-form analytical expression relating the objective values and the design variables does not exist [31], mainly due to the fact that the objective functions are evaluated externally in a different solver or simulation package (see, e.g., [32]). The objective functions in such problems are often expensive to evaluate, which may consist of executing thousands of command lines (e.g., in a CFD code) to complete a single iteration. Other meta-heuristic optimization techniques like, e.g., neural network [33] and particle swarm optimization [34] may also be employed in such blackbox optimization procedure, but they have not been considered here. To the best of our knowledge, until very recently, the automatic linking of the optimization process with CFD codes has not been performed for finding the optimal value of volumetric heating in turbine blades. Since increasing the volumetric heating leads to the reductions of DAR and LND and the increase of ILE, according to the results of the optimization process, there will be an optimal value for the volumetric heating rate to reach the best performance of the steam turbine.

The remainder of this paper is organized as follows. Section 2 starts with some preliminaries regarding the problem. In Section 3, the governing equations of the wet steam flow are reviewed, followed by the steps of the optimization procedure in Section 4. The implementation details of the numerical analysis as well as validation against wellestablished data are presented in Section 5. The effects of volumetric heating on the wet steam flow is numerically investigated in Section 6, and the optimization results are illustrated in Section 7. Section 8 presents some discussions on results and, finally, Section 9 draws some conclusions.

\section{Preliminaries}

Figure 1 shows the model problem that involves the stationary cascade of the steam turbine blade consisting of two converging and diverging parts. The steam flow passes through the cascade between the two turbine blades and reaches the Mach number of $M_{a}=1$ at the throat. Then, the flow is condensed after the throat and, finally, leaves the passage. The inlet and outlet boundary conditions are pressure type and the blade walls are fixed and have the no-slip boundary conditions. The inlet and outlet zones are considered as continuous with periodic boundary conditions in order for the flow to be better simulated. The Eulerian-Eulerian approach and the SST $k-\omega$ turbulence model, developed by Menter [35], are used to analyze the two-dimensional viscous wet steam flow. The mentioned turbulence model is based on the turbulence kinetic energy, $k$, and the specific rate of dissipation, $\omega$. It accounts for wall effects and is suitable for both near- and far-from-the-wall regions. Thus, the turbulence model shows a good accuracy in predicting the condensation shock in two-phase wet steam flows (see, e.g., [36])

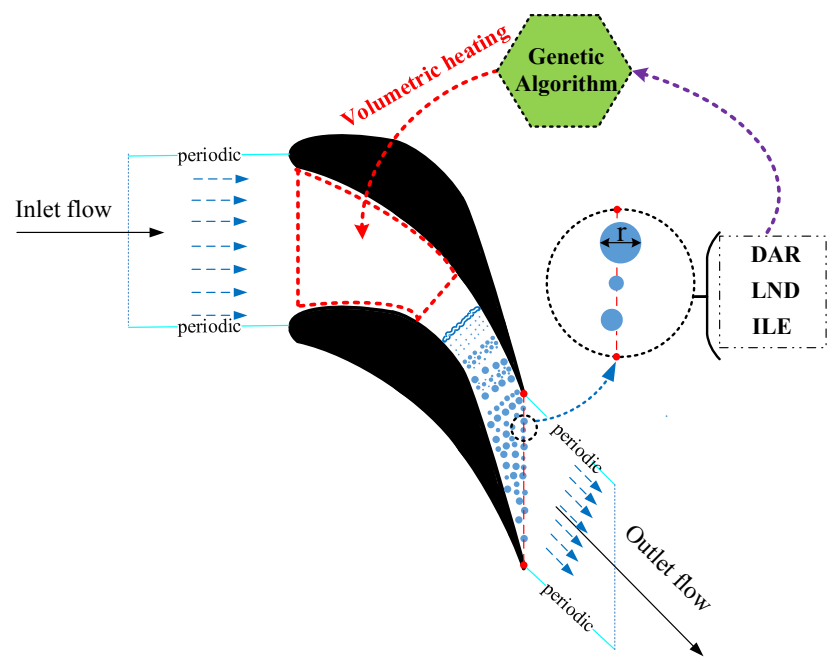

Figure 1: The geometry of the blade turbine, flow passage, and the optimization loop, with objectives measured at the end of the passage.

As shown in Figure 1, it is presumed that the volumetric heating is added to steam flow in the convergent part of the blade and before the throat. The volumetric heating has particular effects on the steam flow, e.g., increases the vapor and saturation temperatures, while decreases the supercooling temperature of the vapor. As a result, the average temperature of the vapor at the throat does not reach the value of the supercooling temperature, and the condensation shock is delayed. Consequently, the shock location is gradually transmitted to the downstream. Furthermore, adding the volumetric heating to the flow in the converging part of the cascade, makes the average temperature of the droplets (i.e., liquid 
phase) to be higher than the adiabatic case after the condensation shock. It leads to the evaporation of some droplets and, hence, reduction of the droplet growth, which reduces wetness fraction and values of DAR and LND at the blade outlet.

Although adding the volumetric heating improves the DAR and LND factors, it leads to the increase of the local entropy (and, thus, the value of ILE), which is an undesirable factor in the steam turbines. Accordingly, the optimal amount of volumetric heating rate should be found in order to reach the best performance of the turbine. For this purpose, a multiobjective optimization procedure is performed with the values of DAR, LND and ILE (measured at the end of the passage) as the objective functions. The required rate of volumetric heating is then considered as the design variable. The optimization problem can be summarized as follows.

$$
\left\{\begin{array}{l}
\text { Find the rate of volumetric heating } Q, \\
\text { which minimizes DAR, LND, and ILE, } \\
\text { subject to boundary conditions. }
\end{array}\right.
$$

\section{Governing equations}

The two-dimensional Navier-Stokes equations, assuming the compressibility and viscosity of the condensed steam flow is used and the Eulerian-Eulerian model is employed. In addition, the liquid mass fraction, the number of droplets and the entropies of both vapor and liquid phases are calculated. The equations represented in this section are used to obtain the objective functions, namely DAR, LND, and ILE.

\subsection{Conservation Equation}

The general forms of conservation equations of mass, momentum, and energy are written as follows [37]:

$$
\begin{aligned}
\frac{\partial \rho}{\partial t}+\frac{\partial}{\partial x_{j}}\left(\rho u_{j}\right) & =0, \\
\frac{\partial}{\partial t}\left(\rho u_{j}\right)+\frac{\partial}{\partial x_{j}}\left(\rho u_{i} u_{j}\right) & =-\frac{\partial P}{\partial x_{j}}+\frac{\partial \tau_{i j}}{\partial x_{j}}, \\
\frac{\partial}{\partial t}(\rho H)+\frac{\partial}{\partial x_{j}}\left(\rho u_{j} H\right) & =\frac{\partial q_{j}}{\partial x_{j}}+\frac{\partial}{\partial x_{j}}\left(u_{i} \tau_{i j}\right),
\end{aligned}
$$

where $H=h+\frac{1}{2} u_{i} u_{i}$ is the total enthalpy, and $q_{j}=-K_{t} \partial T / \partial x_{j}$ is the heat flux.

In all equations, the properties of saturated vapor are calculated based on the properties of both vapor and liquid phases as [9]

$$
\phi_{\text {mix }}=\phi_{l} \beta+(1-\beta) \phi_{v},
$$

where $\phi$ refers to the properties such as enthalpy, entropy, specific heat, and thermal conductivity. The following equations are used for the liquid phase coefficients with liquid mass fraction $\beta$ and number of droplets per volume $\eta$ as [38]:

$$
\begin{aligned}
& \frac{\partial}{\partial t}(\rho \beta)+\frac{\partial}{\partial x_{i}}\left(\rho u_{i} \beta\right)=\Gamma, \\
& \frac{\partial}{\partial t}(\rho \eta)+\frac{\partial}{\partial x_{i}}\left(\rho u_{i} \eta\right)=\rho I,
\end{aligned}
$$

where $\Gamma, I$, and $\rho$ are mass generation rate per unit volume, droplet nucleation rate and density, respectively. The assumptions of these equations include

- the steam pressure is considered as the pressure of the mixture flow;

- the steam temperature is the same as the mixture temperature;

- the volume of droplets is assumed to be negligible;

- the condensation is homogeneous;

- the droplet growth is based on the droplet average radius.

\subsection{Droplet nucleation rate and growth model}

According to the pressure-temperature thermodynamic diagram, when the superheated steam undergoes a quick isentropic expansion, it deviates from its thermodynamic equilibrium state and enters to the non-equilibrium phase that is typically referred to as the supercooled state. This phase change depends on various factors, e.g., the vapor saturation temperature, the supercooled vapor temperature, and the flow regime. The liquid phase density at this state is obtained by

$$
\rho=\frac{\rho_{v}}{1-\beta},
$$

and the Gibbs energy released from the supercooled vapor is [38]

$$
\Delta G=-m_{r} R T_{v} \ln S+4 \pi r^{2} \sigma_{r},
$$

where $S$ represents the supersaturation ratio and is obtained by dividing the flow pressure by the saturation pressure at the vapor's temperature, that is

$$
S=\frac{P}{P_{s a t}\left(T_{v}\right)} .
$$

The thermodynamic equilibrium enforces the supercooled vapor to have a phase change and start nucleating. When the clusters are reached at their final amount and no longer grow, the critical Gibbs free energy variations are [38]

$$
\Delta G^{*}=\frac{16 \pi \sigma_{r}^{3}}{\rho_{l} R T_{v} \ln S}=\frac{4}{3} \pi r^{* 2} \sigma_{r},
$$


Table 1

Constant parameters of the equation of state, employed in Eqs. (17) and (18).

\begin{tabular}{llllllllll}
\hline$\tau_{0}(-)$ & $\tau_{1}(-)$ & $\tau_{2}(-)$ & $\alpha_{1}(\mathrm{~K})$ & $\alpha_{2}(-)$ & $b_{1}\left(\mathrm{~m}^{3} / \mathrm{kg}\right)$ & $b_{2}\left(\mathrm{~m}^{3} / \mathrm{kg}\right)$ & $b_{3}\left(\mathrm{~m}^{3} / \mathrm{kg}\right)$ & $b_{4}\left(\mathrm{~m}^{6} / \mathrm{kg}^{2}\right)$ & $b_{5}\left(\mathrm{~m}^{6} / \mathrm{kg}^{2}\right)$ \\
\hline 0.89780 & $1500 / T$ & $T / 647.286$ & 10000 & 11.16 & 0.0015 & $942 \times 10^{-3}$ & $-488.2 \times 10^{-6}$ & 1.722 & $1.5 \times 10^{-6}$ \\
\hline
\end{tabular}

Table 2

Constant parameters employed in Eq. (19) for entropy calculation.

\begin{tabular}{lllllll}
\hline$a_{1}\left(\mathrm{~kJ} / \mathrm{kg} \mathrm{K}^{1}\right)$ & $a_{2}\left(\mathrm{~kJ} / \mathrm{kg} \mathrm{K}^{2}\right)$ & $a_{3}\left(\mathrm{~kJ} / \mathrm{kg} \mathrm{K}^{3}\right)$ & $a_{4}\left(\mathrm{~kJ} / \mathrm{kg} \mathrm{K}^{4}\right)$ & $a_{5}(\mathrm{~kJ} / \mathrm{kg} \mathrm{K})^{5}$ & $a_{6}(\mathrm{~kJ} / \mathrm{kg} \mathrm{K})^{6}$ & $s_{c}(\mathrm{~kJ} / \mathrm{kg} \mathrm{K})$ \\
\hline 0.89780 & $1500 / T$ & $T / 647.286$ & 10000 & 11.16 & 0.0015 & 970.12 \\
\hline
\end{tabular}

being $r^{*}$ the Kelvin-Helmholtz critical droplet radius defined as a function of the droplets' surface tension and density, as well as the supersaturation ratio [39], that is

$$
r^{*}=\frac{2 \sigma_{r}}{\rho_{l} R T_{v} \ln S}
$$

According to the classical theory of nucleation, the droplet nucleation rate is obtained by the critical radius and surface tension of droplets as shown in, e.g., [40]

$$
I_{\text {classic }}=q_{c} \frac{\rho_{v}^{2}}{\rho_{l}} \sqrt{\frac{2 \sigma_{r}}{\pi M_{m}^{3}}} \exp \left(-\frac{4 \pi r^{* 2} \sigma_{r}}{3 K_{b} T_{v}}\right),
$$

and then corrected by the non-isothermal correction coefficient, $\theta$, in the following form [41]

$$
I=\frac{1}{1+\theta} I_{\text {classic }},
$$

given

$$
\theta=\frac{2(\gamma-1)}{\gamma+1} \frac{h_{m i x}}{R T}\left(\frac{h_{m i x}}{R T}-\frac{1}{2}\right) .
$$

Based on the classical nucleation theory of droplets, the mass generation rate is calculated as the summation of the increased mass caused by both the existence of droplets and the generated droplets given by [40]

$$
\Gamma=\frac{4}{3} \pi \rho_{l} I r^{* 3}+4 \pi \rho_{l} \eta \bar{r}^{2} \frac{\partial \bar{r}}{\partial t},
$$

noting that the rate of radius variation over time (i.e., the droplet growth rate) is

$$
\frac{\partial \bar{r}}{\partial t}=\frac{P}{h_{\text {mix }} \rho_{l} \sqrt{2 \pi r T}} \frac{\gamma+1}{2 \gamma} C_{p}\left(T_{l}-T_{v}\right) .
$$

and $T_{l}$ and $T_{v}$ are the droplet and vapor temperatures, respectively, obtained from the saturation temperature as

$$
T_{l}=T_{\text {sat }}-\left(T_{\text {sat }}-T_{v}\right) \frac{r^{*}}{r} .
$$

Finally, the number of droplets per unit volume is given as

$$
\eta=\frac{\beta}{(1-\beta)\left(\rho_{l} / \rho_{v}\right) V_{d}},
$$

where $V_{d}=4 \pi \bar{r}^{3} / 3$ is the average volume of the generated droplets.

\subsection{Equation of state}

The equation of state describing the relation between the pressure, temperature, and the density of the vapor is given by (see, e.g., [42])

$$
P=\rho_{v} R T\left(1+B_{2} \rho_{v}+B_{3} \rho_{v}^{2}\right),
$$

where $B_{2}$ and $B_{3}$ are the second and third virial coefficients expressed as

$$
\begin{aligned}
B_{2}= & b_{1}\left(1+T / \alpha_{1}\right)^{-1} \\
& +b_{2} \exp \left(\tau_{1}\right)\left[1-\exp \left(-\tau_{1}\right)\right]^{5 / 2} \tau_{1}^{-1 / 2}+b_{3} \tau_{1}, \\
B_{3}= & b_{4}\left(\tau_{2}-\tau_{0}\right) \exp \left(-\alpha_{2} \tau_{2}\right)+b_{5},
\end{aligned}
$$

with constants tabulated in Table 1.

\subsection{Entropy calculation}

The entropy of the liquid and vapor phases are calculated as (see, e.g., [42])

$$
\begin{aligned}
s_{l}= & C_{l} \ln \left(\frac{T_{l}}{T_{D}}\right), \\
s_{v}= & \int\left(\sum_{i=1}^{6} a_{i} T^{i-2}\right) d T \\
& -R\left[\ln \rho_{v}+\left(B_{2}+T \frac{d B_{2}}{d T}\right) \rho_{v}\right. \\
& \left.+\frac{1}{2}\left(B_{3}+T \frac{d B_{3}}{d T}\right) \rho_{v}^{2}\right]+s_{c},
\end{aligned}
$$

where $T_{D}$ is the reference temperature and the other constants of the entropy equation are tabulated in Table 2. Given the entropies of the liquid and vapor phases, the entropy of the two-phase flow is then obtained using Eq. (3).

\section{Optimization process}

As stated earlier, three parameters of droplet average radius (DAR), logarithm of number of droplets per volume (LND), and the integral of local entropy (ILE), measured at the end of the cascade, are considered as the objectives 


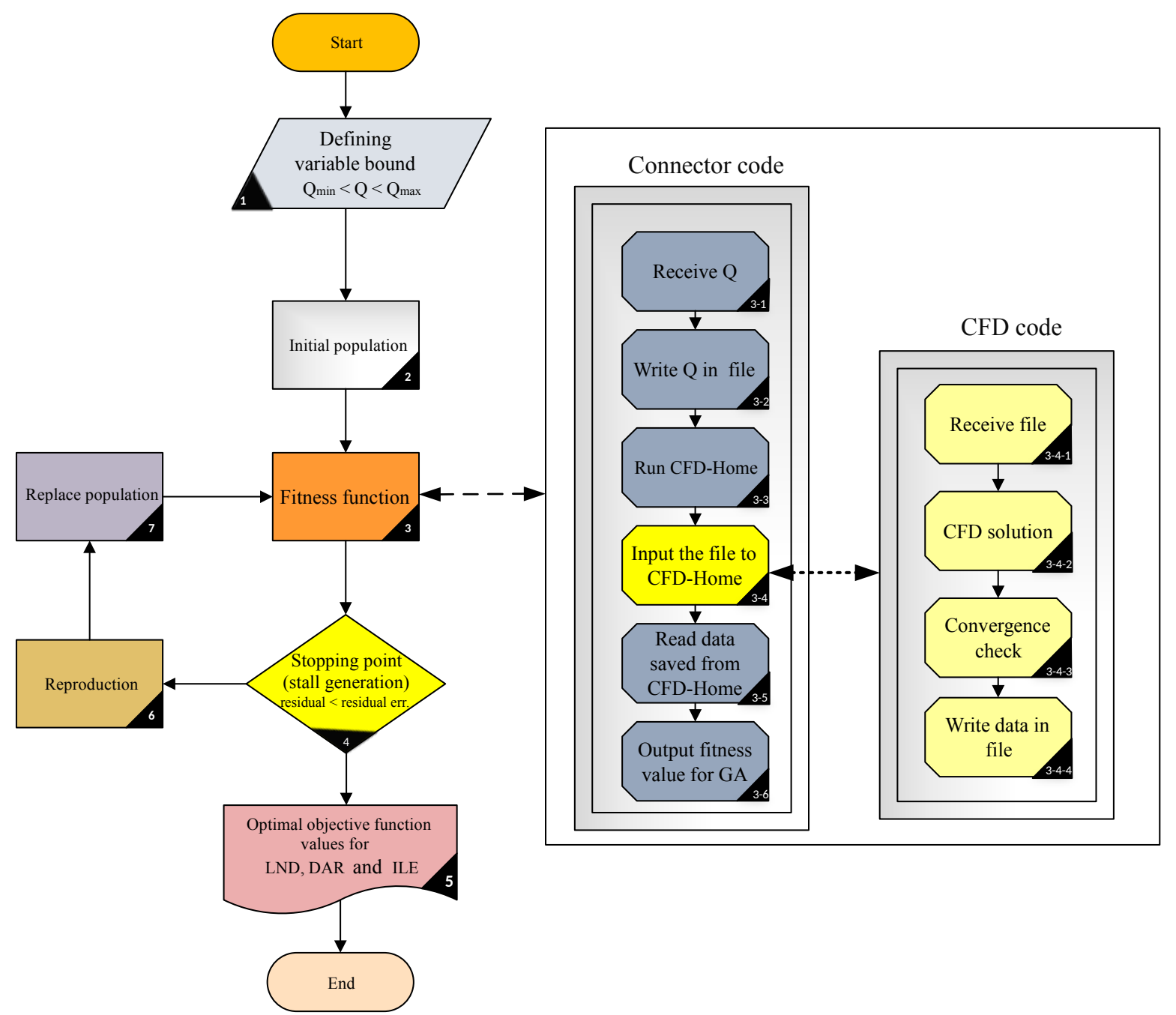

Figure 2: Flowchart of the blackbox optimization process consists of three blocks: GA (main part), connector, and CFD codes.

that should be reached at minimum values through a multiobjective optimization process. Based on the formulation represented in Section 3, the objectives are defined as

$$
\begin{aligned}
\text { DAR } & :=\frac{1}{A} \int_{A} \bar{r} d A, \\
\text { LND } & :=\frac{1}{A} \int_{A} \log _{10}(\eta) d A, \\
\text { ILE } & :=\int_{A} \rho u s d A, \quad \text { measured at } X=L,
\end{aligned}
$$

where $X=0 \sim L$ is the length parameter, being $L$ the total length of the blade. In order to perform the global optimization process, the CFD code as a blackbox function is employed that is automatically linked to the GA code. More precisely, this procedure consists of three different parts (see Figure 2), namely the multiobjective GA code (main part), the CFD code, and the connector code that automatically links the other two parts. In this loop, the input of the CFD code is determined by the GA part (referred to as the population). The problem is then numerically solved by the CFD code and the integrated data is stored as the output of solution. This output is identified and analyzed as the targets (i.e., objectives) of the multiobjective GA, followed by the next input in the next iteration (referred to as the generation), and the loop continues until the desired convergence in results is reached. The connector code, meanwhile, is rewriting the required lines in the CFD code and also reads the output file. More details regarding the steps of performing the optimization process is demonstrated in Figure 2.

Since evaluating the objective functions at each iteration entails solving a CFD problem, which is performed outside the optimization code, the whole process is typically referred to as the blackbox optimization. The main advantages of this algorithm is that it can be linked to a variety of CFD codes in different applications. Herein, two sets of iterative procedures are considered, one in terms of population/generations of the GA algorithm, which is checked by a stall criteria (typically measured by a residual), and the other inside the CFD run for solving the problem of the wet steam flow, which is checked by the convergence of the solution. 


\section{Implementation prerequisites}

\subsection{Implementation details}

In this paper, the numerical solution is adopted by using two-dimensional Reynolds averaged Navier-Stokes (RANS) equations. The conservation equations governing the solution field (which includes the steam mixture consisting of the liquid and the vapor phases) is described by using the finite volume integration method. In this regard, an EulerianEulerian approach is employed by using the SST $k-\omega$ turbulence modeling. When simulating with Eulerian-Eulerian method, it is not necessary to determine the flow path from one cell to another. Thus, knowing the conditions of the fluid leaving the cell is not required. It facilitates the solution of equations. It is confirmed by other researches that this approach provides acceptable results in wet steam flow simulations (see, e.g., [43]).

The effects of volumetric heating are investigated by testing with different heating rates in the range of $0.0 \sim 8.0 \times 10^{8} \mathrm{~W} / \mathrm{m}^{2}$. The volumetric heating has different effects on the characteristics of the flow as will be discussed in Section 6. Then, by performing the optimization loop, the optimal volumetric heating rate is obtained considering the three objectives of DAR, LND, and ILE (see Section 7). This optimal value is compared with the adiabatic case (i.e., without volumetric heating).

The global optimization toolbox of MATLAB environment is implemented for performing the genetic algorithm and automatically connecting the CFD code and the optimization procedure. CFD simulations are performed by ANSYS Fluent. The simulations are density-based and the wet steam model is employed based on the Eulerian-Eulerian approach. The droplet nucleation rate and growth model are also implemented by this commercial fluid simulation software. The computations are conducted on a $2.30 \mathrm{GHz} \mathrm{In}-$ tel Xeon E5 CPU with 20 processors and using 64 GB of RAM, where 19 processors are allocated to run the CFD block (see Figure 2) and one processor for the GA and connector blocks.

\subsection{Grid dependence study}

In order to find the suitable grid for flow simulation, a mesh study with different grid sizes is conducted and the computed values of static pressure on the suction and pressure walls through the blade length are plotted in Figure 3.

The importance of using the pressure graph is in the fact that the suction side can well represent the condensation shock. Herein and in the following, the chord ratios of $X / L=0$ and 1 are denoting the inlet and outlet of the cascade, respectively. Testing with different grid sizes indicates that the grid of $18 \times 200$ can be selected, considering that finer grids do not show a significant change is results.

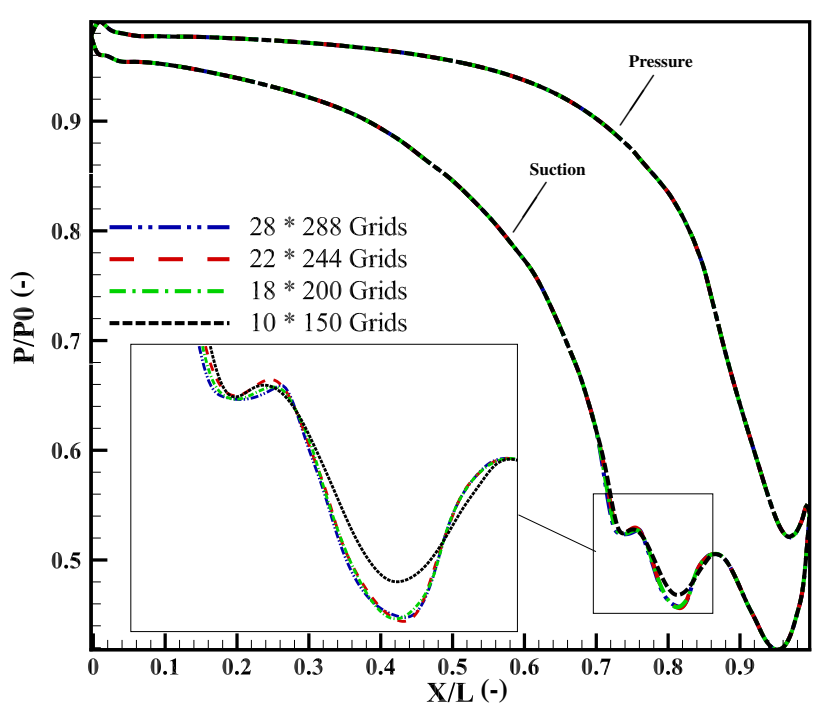

Figure 3: Grid dependence study for the results of the static pressure on suction and pressure walls of the cascade.

\subsection{Validation}

In order to validate the accuracy of the numerical modeling, the simulated values of pressure and droplet average radius throughout the cascade are compared in Figure 4 with the well-established experimental data of Bakhtar et al. [44]. Herein, two different practical cases are considered: the supersonic outlet flow with $P_{\text {out }} / P_{0}=0.48$, and the subsonic outlet flow with $P_{\text {out }} / P_{0}=0.57$. The results of pressure show a good consistence with the experimental data. For the droplet radius, only the experimental data at the end of the cascade is checked that shows an acceptable accuracy (note that this is a common difference between experimental and numerical results as reported in, e.g., [20]).

\section{Effect of volumetric heating on wet steam flow}

Before proceeding with the optimization results, it is essential to study in detail the effect of volumetric heating on the flow characteristics. Section 2 briefly described the trend that the flow encounters by adding the volumetric heating. It is important to consider that when the steam flow passes through the throat, the velocity reaches at $M_{a}=1$ and the temperature decreases. If the decreasing temperature reaches the supercooling temperature of the vapor, the flow enters to the thermodynamic non-equilibrium phase and begins to condense. This section investigates the effect of volumetric heating on the first case study (i.e., the supersonic outlet). In Figure 5a, the construction and growth of droplets in the diverging part of the cascade is illustrated for the adiabatic case (i.e., without volumetric heating). Adding the volumetric heating to the flow lowers down the supercooling temperature at the throat, and therefore, delays the condensation (see Figure $5 b$ ). Moreover, the average temperature 


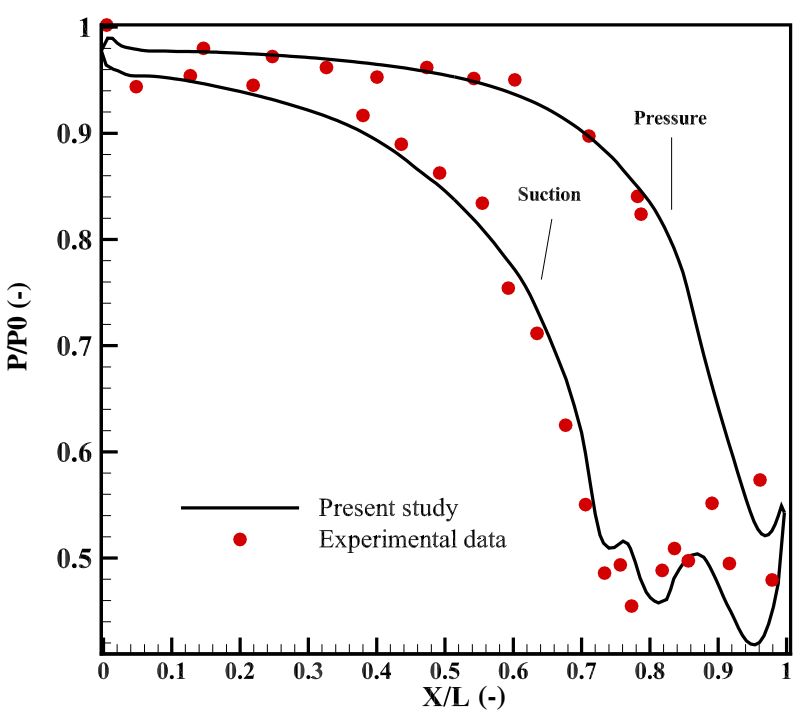

(a) Static pressure (supersonic outlet)

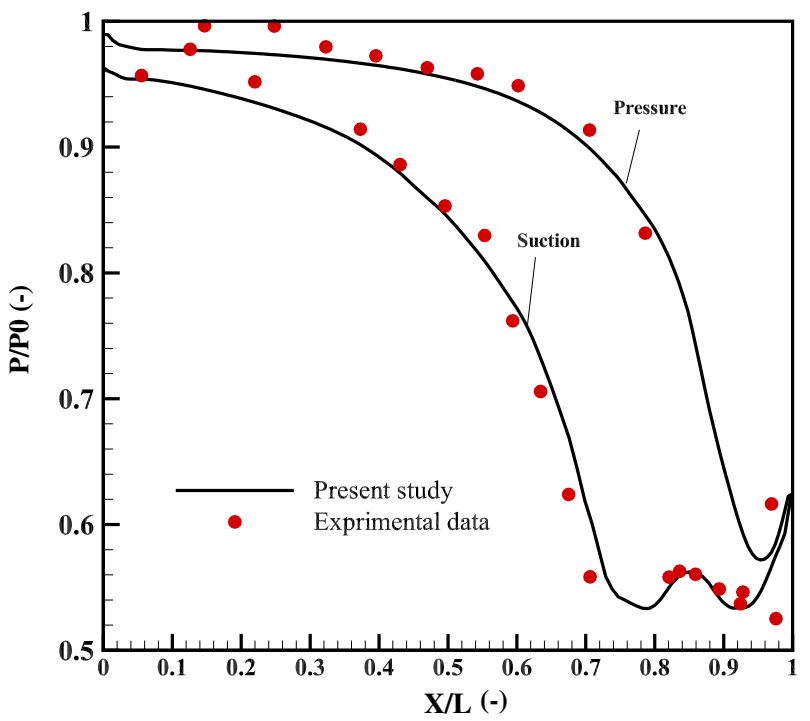

(c) Static pressure (subsonic outlet)

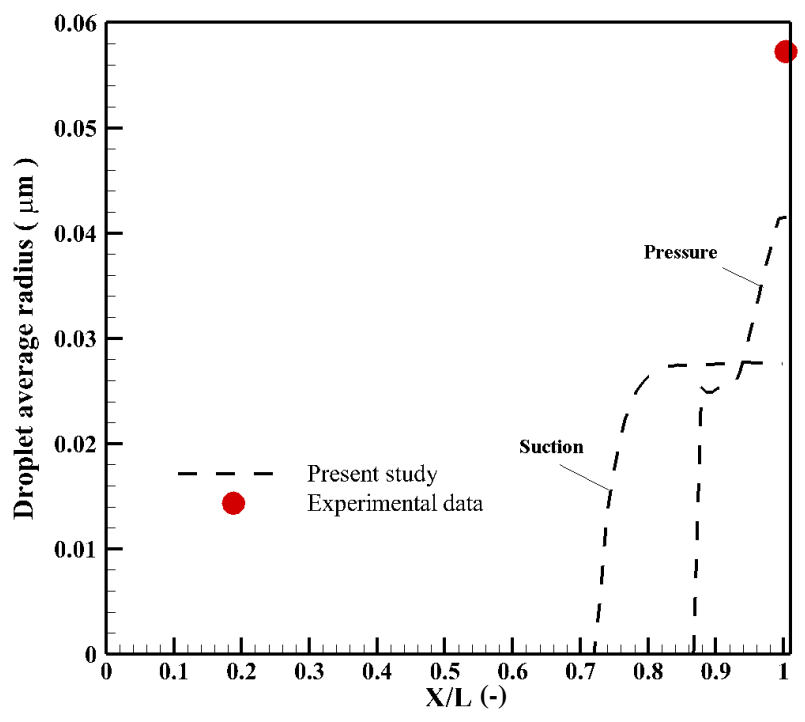

(b) Droplet radius (supersonic outlet)

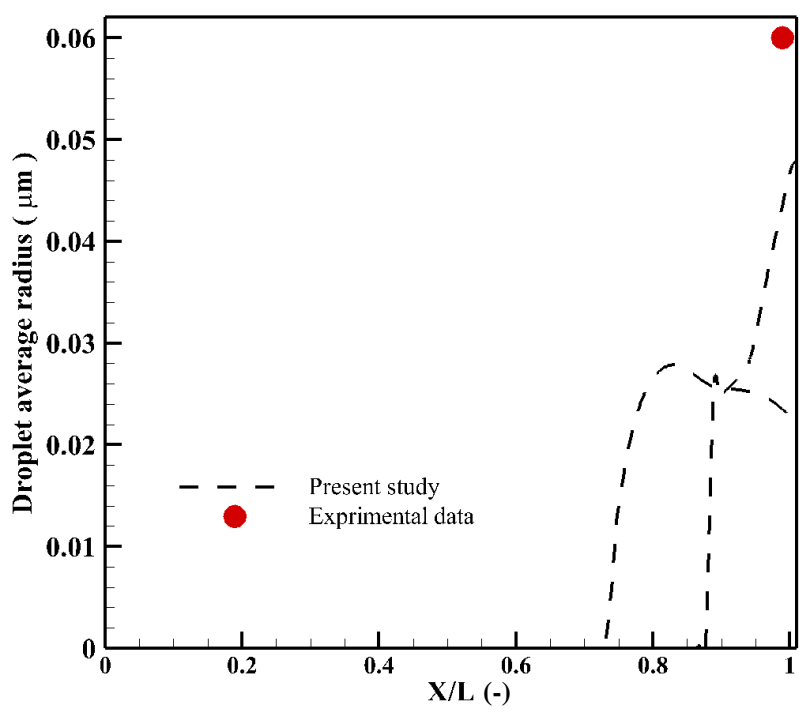

(d) Droplet radius (subsonic outlet)

Figure 4: Result validation against experimental data of [44] for the static pressure and droplet average radius. Two practical cases: (a,b) $P_{\text {out }} / P_{0}=0.48$ and $T_{0}=T_{\text {sat }}-8 \mathrm{~K}$, (c,d) $P_{\text {out }} / P_{0}=0.57$ and $T_{0}=T_{\text {sat }}-8 \mathrm{~K}$. The reported values are on the suction and pressure walls of the blade throughout the cascade.

of the droplets becomes higher than the adiabatic case, resulting in evaporation of some droplets. By increasing the heating rate to $8.0 \times 10^{8} \mathrm{~W} / \mathrm{m}^{2}$, the supercooling temperature becomes negative, and by definition, we have a superheated steam flow, so that the condensation shock does not happen as demonstrated in Figure 5c. The effect of different rates of volumetric heating on the droplet radius on the centerline of the passage is illustrated in Figure 5d. This figure reveals that the location of formation of first droplets is moved from $X / L \approx 0.75$ for the adiabatic case toward the outlet of the passage for higher volumetric heating rates. Additionally, the value of DAR $=\left.\frac{1}{A} \int_{A} \bar{r}\right|_{X / L=1} d A$ as one of objective functions is reduced. It can also be seen that for $Q>6.0 \times 10^{8} \mathrm{~W} / \mathrm{m}^{2}$, the droplet radius and its growth is negligible.

Figure 6 investigates the effect of increasing the volumetric heating rate on the pressure distribution. It is important to note that because of the geometry of the blade, the pressure is reduced throughout the passage, until the condensation shock happens. This shock is observed as the first pressure rise in the flow (see point 1 in Figure $6 \mathrm{~d}$ and point $1^{*}$ as its counterpart on the centerline in Figure 6e). This pressure rise is due to the heat transfer between droplets and vapor. The pressure then decreases further until the first aerodynamic shock happens in order to adjust the pressure in accordance with the large back-pressure at the end of the blade. The aerodynamic shock is first observed near $X / L=1$ on the pressure side and then reflected on the suc- 


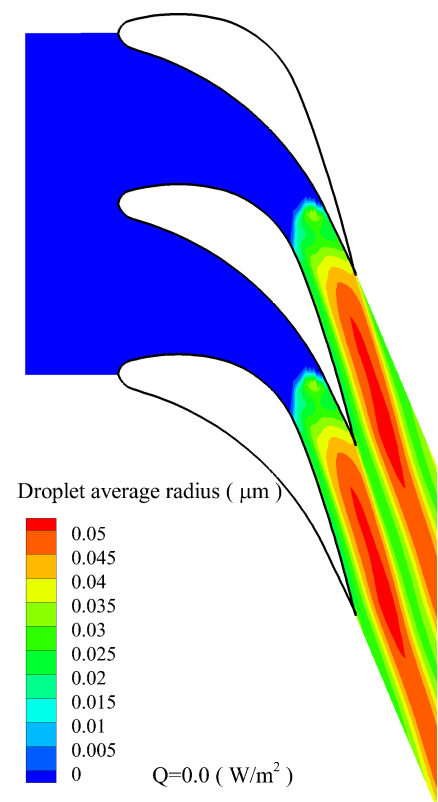

(a)

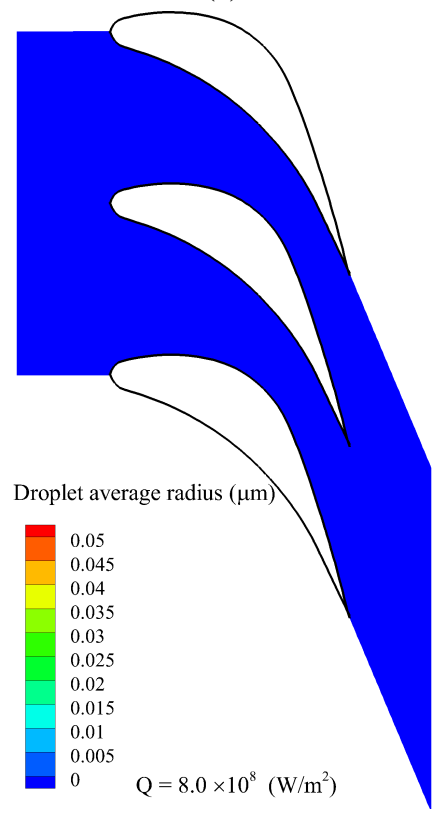

(c)

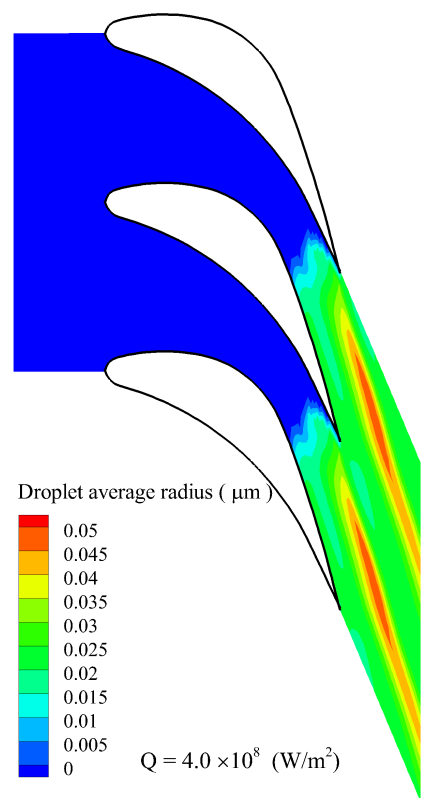

(b)

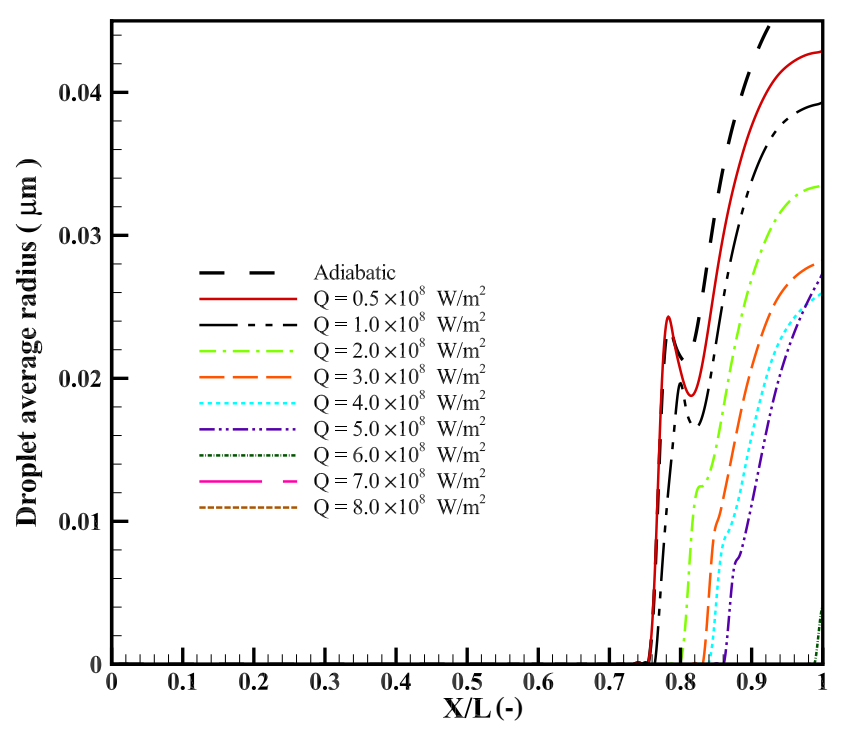

(d)

Figure 5: (a,b,c) Contours of droplet average radius throughout the cascade for $Q=0.0$ (adiabatic case), $Q=4.0 \times 10^{8} \mathrm{~W} / \mathrm{m}^{2}$, and $Q=8.0 \times 10^{8} \mathrm{~W} / \mathrm{m}^{2}$. (d) The effect of different volumetric heating rates on the distribution of droplet average radius over the centerline of the passage. The construction and growth of droplets are delayed by increasing the rate of $Q$. Note the negligible droplet radius for $Q>6.0 \times 10^{8} \mathrm{~W} / \mathrm{m}^{2}$.

tion side (points 2 and 3, respectively). Whereas, the corresponding points of the reflected shock on the centerline are points $2^{*}$ and $3^{*}$. After further decrement of pressure (due to the geometry of the blade), the second aerodynamic shock happens on the suction side near the passage outlet (point 4). It is clear that the reflection of this shock on the centerline (point $4^{*}$ ) can be observed after $X / L=1$.

Figure 6 also illustrates the effect of volumetric heating on the pressure distribution. It can be seen that by adding the volumetric heating, the location of the condensation shock is moved toward the downstream and its magnitude is also decreased. For $Q>6.0 \times 10^{8} \mathrm{~W} / \mathrm{m}^{2}$, no pressure increase can be observed at point 1 on the suction side, denoting the fact that no droplets are constructed (as already shown in Figure 5). However, a greater aerodynamic shock is observed in this case to adjust with the back-pressure at the outlet.

In the next step, the effect of volumetric heating on 


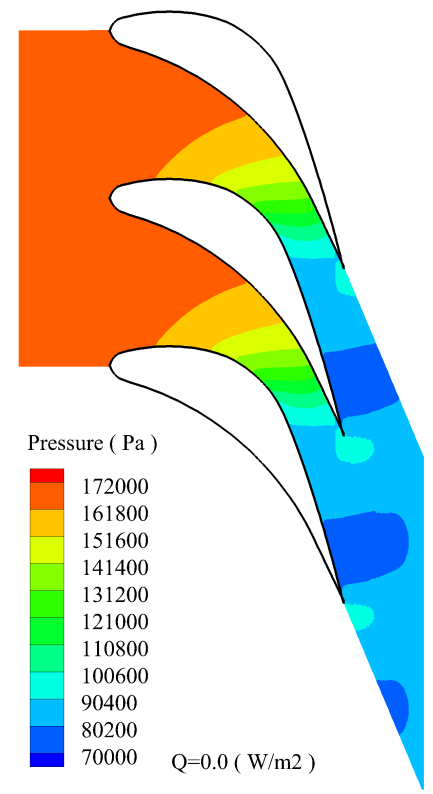

(a)

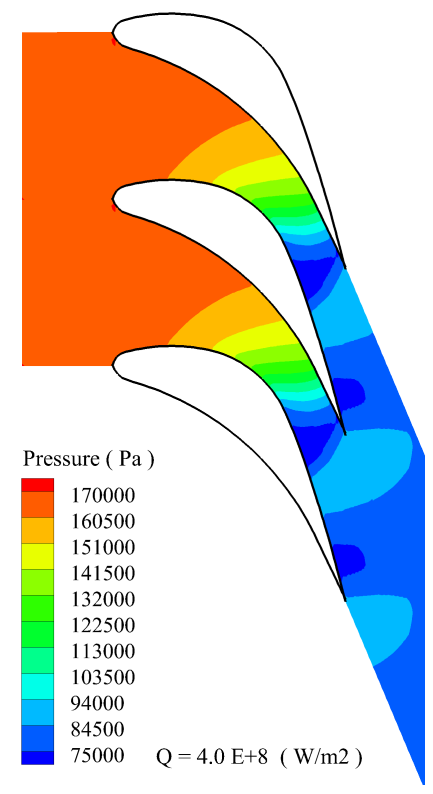

(b)

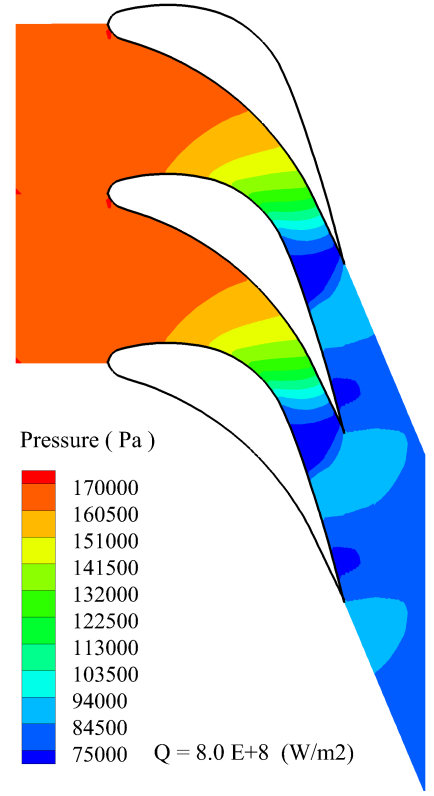

(c)

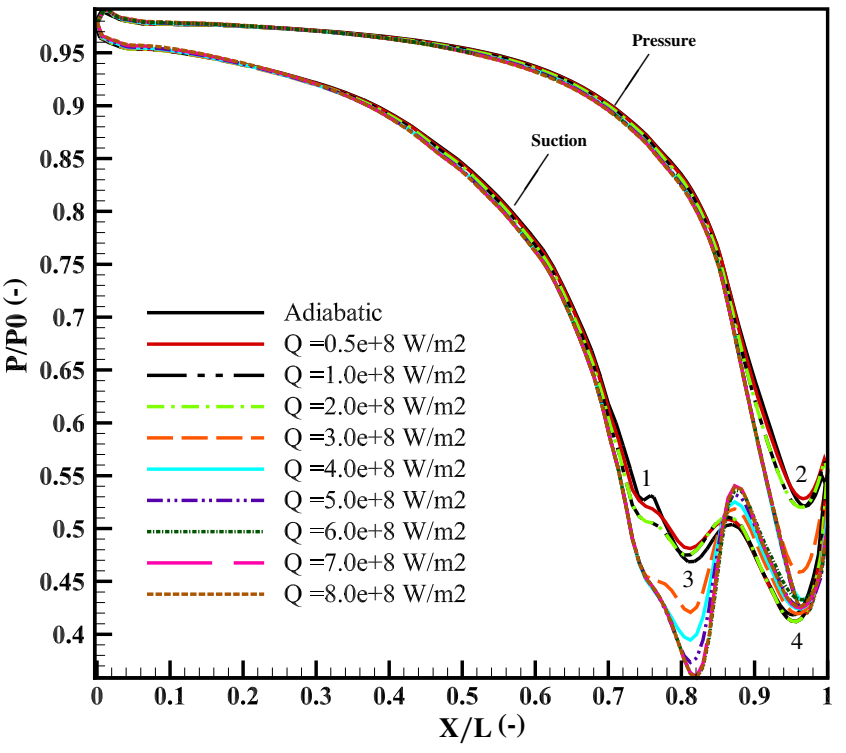

(d)

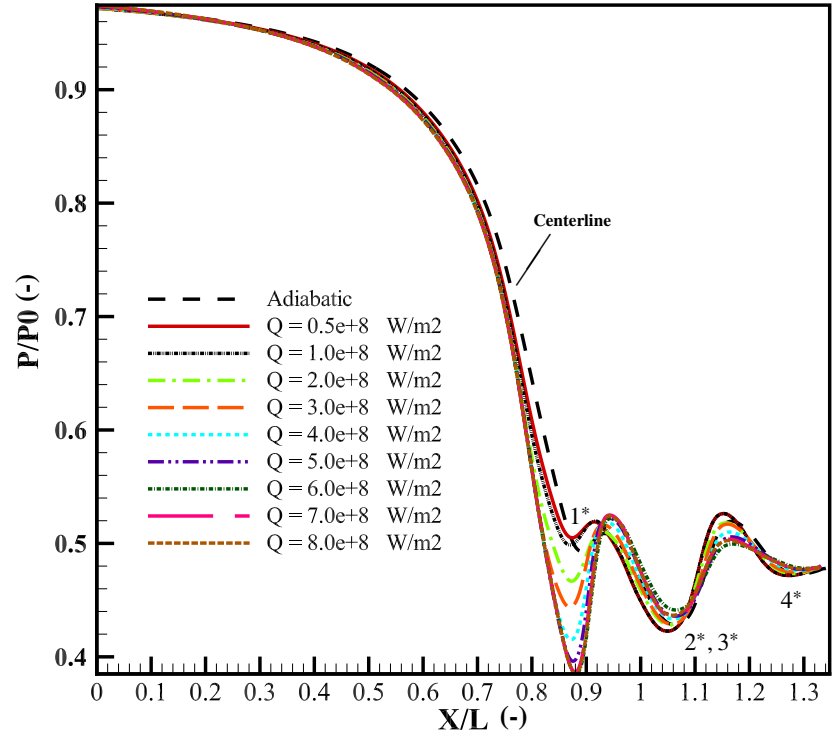

(e)

Figure 6: (a,b,c) Contours of static pressure distribution throughout the cascade for $Q=0.0$ (adiabatic case), $Q=4.0 \times 10^{8} \mathrm{~W} / \mathrm{m}^{2}$, and $Q=8.0 \times 10^{8} \mathrm{~W} / \mathrm{m}^{2}$. The effect of different volumetric heating rates on the pressure distribution are shown over the suction and pressure sides (d), and on the centerline of the passage (e). Note the corresponding positions of the condensation, aerodynamic and reflected shocks on pressure graphs in parts (d) and (e).

the wetness fraction $(\beta)$ is analyzed. Wetness fraction is generally defined as the mass fraction of liquid droplets in the two-phase flow. The wetness fraction contours of different cases with $Q=0.0 \mathrm{~W} / \mathrm{m}^{2}, 4.0 \times 10^{8} \mathrm{~W} / \mathrm{m}^{2}$, and $8.0 \times 10^{8} \mathrm{~W} / \mathrm{m}^{2}$ are plotted in Figure 7. According to figure, it is clear that by increasing the volumetric heating rate, the wetness fraction in the diverging part of the cascade decreases, resulting in a lower wetness at the end of the passage (see Figure 7d). Referring to Eq. (16), which relates the wetness to number of droplets $(\eta)$, the importance of studying this graph lies in the fact that the value of $\mathrm{LND}=\left.\frac{1}{A} \int_{A} \log _{10}(\eta)\right|_{X / L=1} d A$ is reduced by increasing the rate of $Q$.

Finally, it should be pointed out that adding volumetric heating to the flow generally increases the temperature. Therefore, as expressed in Eq. (19), the entropy of both liq- 


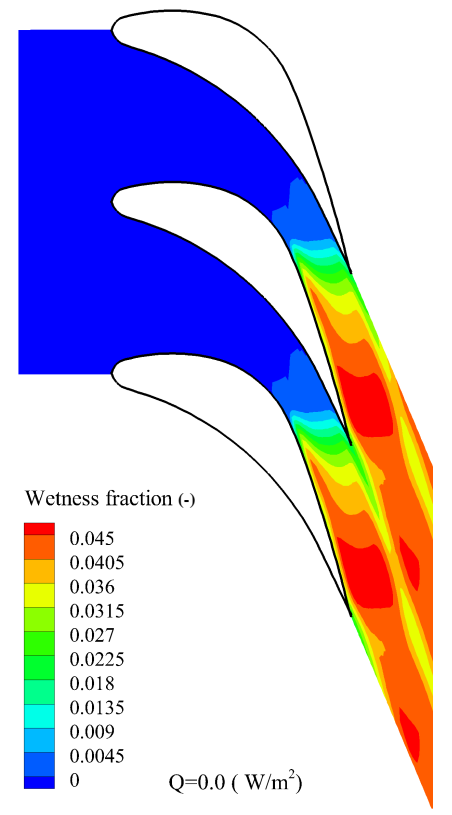

(a)

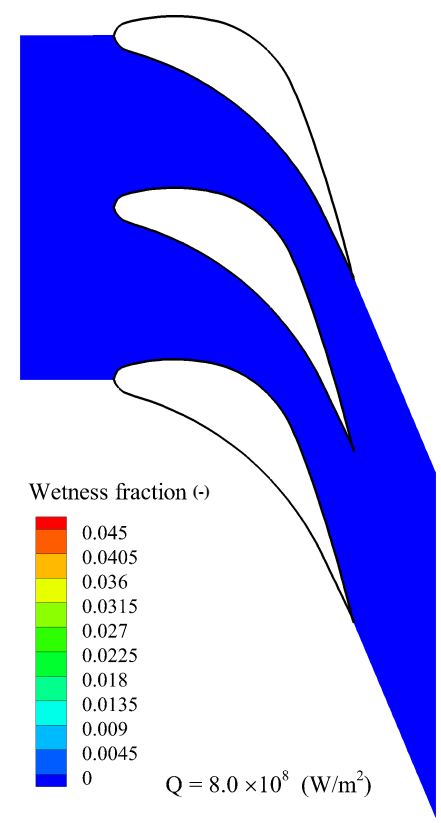

(c)

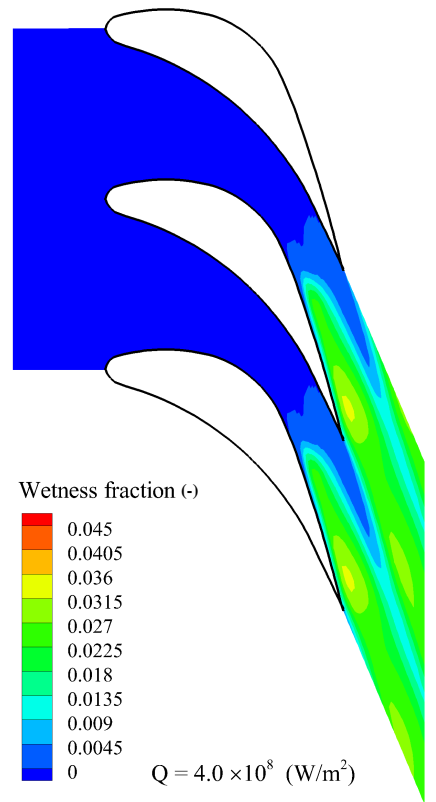

(b)

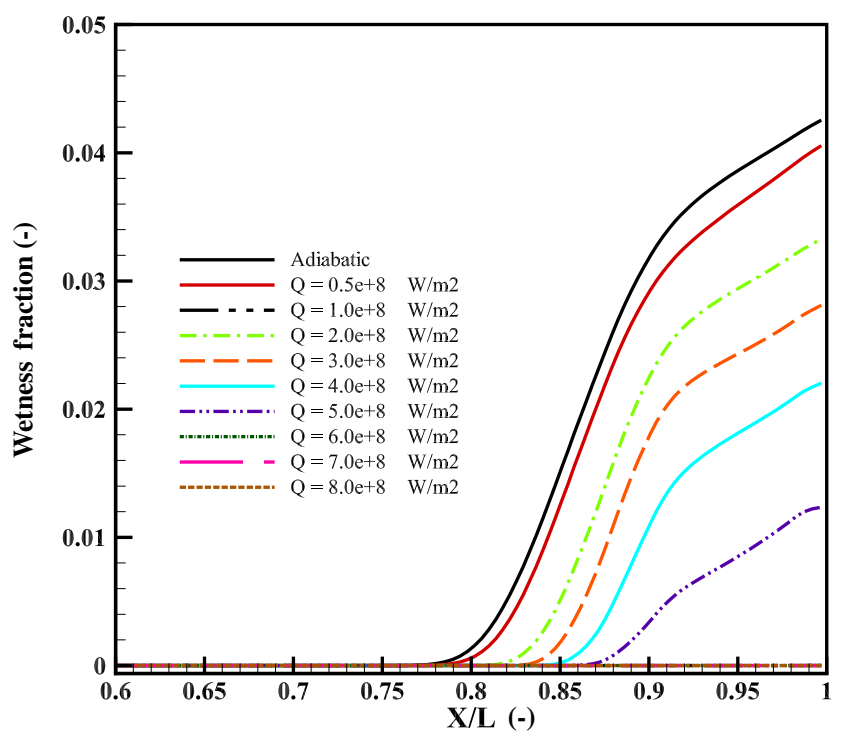

(d)

Figure 7: (a,b,c) Contours of the wetness fraction throughout the cascade for $Q=0.0$ (adiabatic case), $Q=4.0 \times 10^{8} \mathrm{~W} / \mathrm{m}^{2}$, and $Q=8.0 \times 10^{8} \mathrm{~W} / \mathrm{m}^{2}$. (d) The effect of different volumetric heating rates on the wetness over the centerline of the passage. Note the negligible wetness fraction for $Q>6.0 \times 10^{8} \mathrm{~W} / \mathrm{m}^{2}$.

uid and vapor phases increases. When the condensation shock happens and the liquid droplets start growing, since the entropy of the liquid phase is smaller than that of the vapor phase, the entropy of the mixture reveals a decreasing trend. Nevertheless, by increasing the heating rate, the entropy of the flow increases throughout the passage, which is not a desirable trend in steam turbines. Figure 8 depicts the effects of volumetric heating on the entropy contours as well as the entropy distribution over the centerline.
Based on the different effects that adding the volumetric heating can have on the flow, herein, the trends of the objectives (i.e., DAR, LND, and ILE) as a function of $Q$ are summarized. As stated earlier, increasing the volumetric heating rate leads to the reductions of DAR and LND, while increases the ILE. Since the latter is not a desirable outcome, reaching a compromise in the values of the objectives is needed to find the best (i.e., optimal) rate for $Q$. Therefore, conducting a multiobjective optimization is es- 


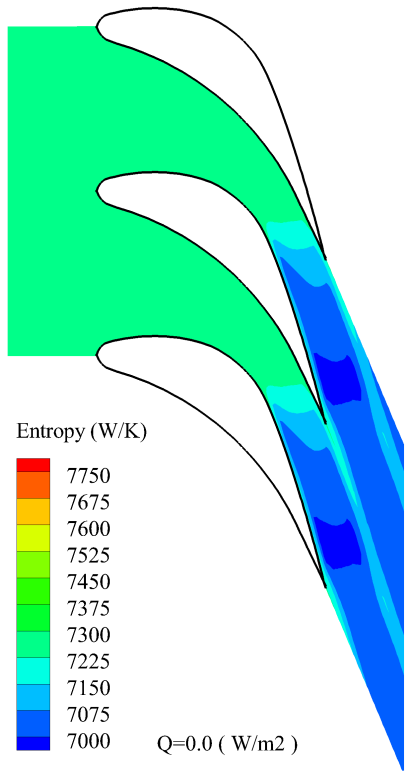

(a)

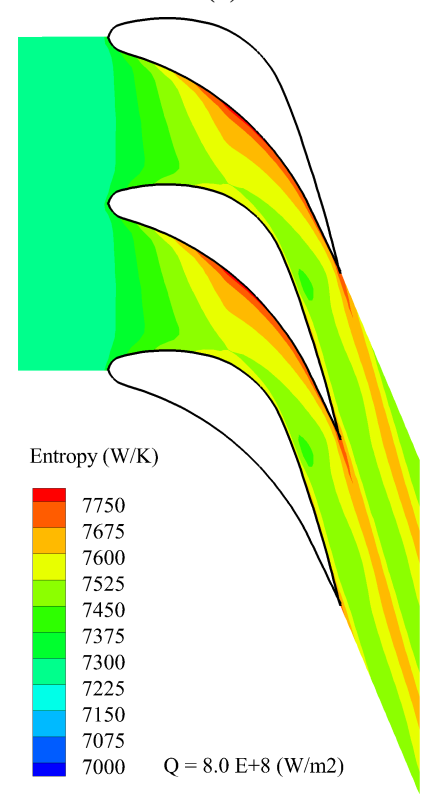

(c)

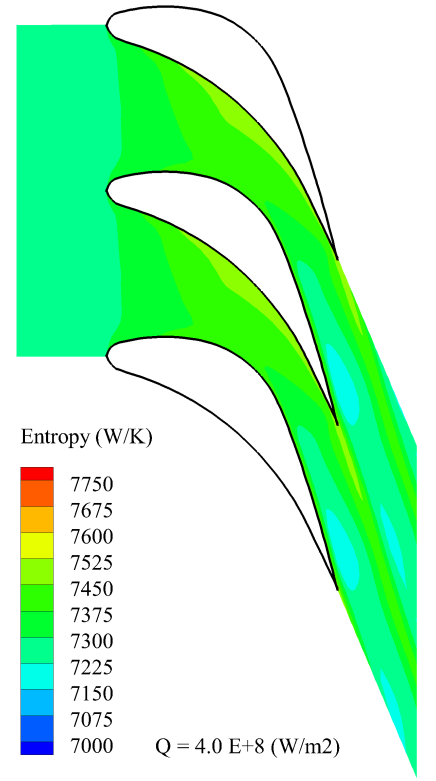

(b)

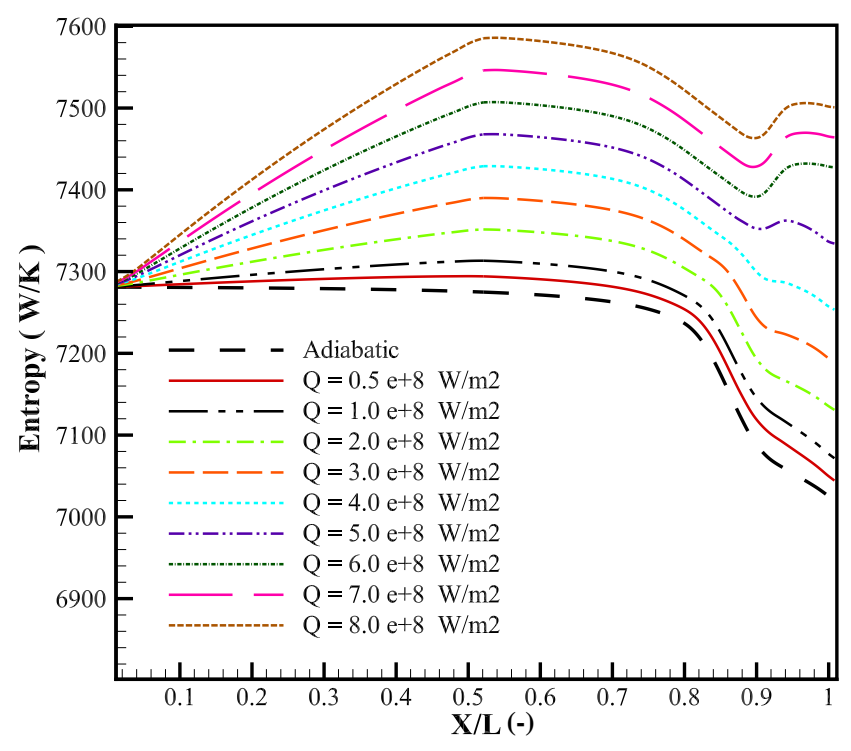

(d)

Figure 8: Effects of different volumetric heating rates on the entropy contours (a,b,c) and the entropy distribution over the centerline (d).

sential, which is investigated in Section 7.

\section{Optimization results}

Considering the effects of volumetric heating on the flow and also taking into account that higher heating rates entail additional cost of power generation, finding an optimal value for $Q$ is essential. For this purpose, a blackbox multiobjective optimization is performed, where the objective functions are evaluated through a set of CFD runs for which the respective inputs are automatically controlled by the optimization loop (see Figure 2). The optimization process is based on the genetic algorithm and is performed under the settings tabulated in Table 3.

Figure 9 demonstrates the convergence of the optimization process for the supersonic outlet case. The convergence rate is measured in terms of the average distance between individuals (i.e., different values of $Q$ selected by the GA algorithm) versus the number of generations (i.e., iterations). The convergence criterion is in accordance with the residual error threshold reported in Table 3.

The optimized values of DAR, LND, and ILE as objective functions and the optimal rate of volumetric heating as the design variable are reported in Table 4 for two case studies with supersonic and subsonic outflows. Accordingly, the 
Table 3

Parameter settings of the multiobjective optimization process.

\begin{tabular}{ll}
\hline Parameter & Value \\
\hline Design variable range, $Q\left(\mathrm{~W} / \mathrm{m}^{2}\right)$ & {$[0.0,8.0] \times 10^{8}$} \\
Maximum No. of iterations of the optimization (-) & 150 \\
Residual error threshold of objective functions (\%) & $1 \times 10^{-4}$ \\
Maximum No. of iterations of CFD solution (-) & 12,000 \\
Convergence threshold of CFD solution (\%) & $1 \times 10^{-6}$ \\
\hline
\end{tabular}

Table 4

The optimized values of DAR, LND, and ILE, the optimal rate of volumetric heating $Q$, the total required heating rate, and the heating transfer area for different cases of supersonic and subsonic outflows.

\begin{tabular}{llllllllll}
\hline $\begin{array}{l}P_{\text {out }} / P_{0} \\
(-)\end{array}$ & $\begin{array}{l}\text { DAR } \\
(\mu \mathrm{m})\end{array}$ & $\begin{array}{l}\text { Improved } \\
\text { by }\end{array}$ & $\begin{array}{l}\text { LND } \\
\left(1 / \mathrm{m}^{3}\right)\end{array}$ & $\begin{array}{l}\text { Improved } \\
\text { by }\end{array}$ & $\begin{array}{l}\text { ILE } \\
(\mathrm{kW} / \mathrm{K})\end{array}$ & $\begin{array}{l}\text { Degraded } \\
\text { by }\end{array}$ & $\begin{array}{l}\text { Volumetric heating } \\
\text { rate } Q\left(\mathrm{~W} / \mathrm{m}^{2}\right)^{*}\end{array}$ & $\begin{array}{l}\text { Total heating } \\
\text { rate }(\mathrm{KW}) *\end{array}$ & $\begin{array}{l}\text { Heat transfer } \\
\text { area }\left(\mathrm{m}^{2}\right)\end{array}$ \\
\hline 0.48 & 0.022 & $45.7 \%$ & 15.88 & $6.0 \%$ & 7.39 & $4.6 \%$ & $5.21 \times 10^{8}$ & 90.64 & $1.74 \times 10^{-4}$ \\
\hline 0.57 & 0.018 & $57.5 \%$ & 15.53 & $7.8 \%$ & 7.78 & $8.8 \%$ & $4.67 \times 10^{8}$ & 81.25 & $1.74 \times 10^{-4}$ \\
\hline
\end{tabular}

* The heating rates are reported for the unit width of the blade.

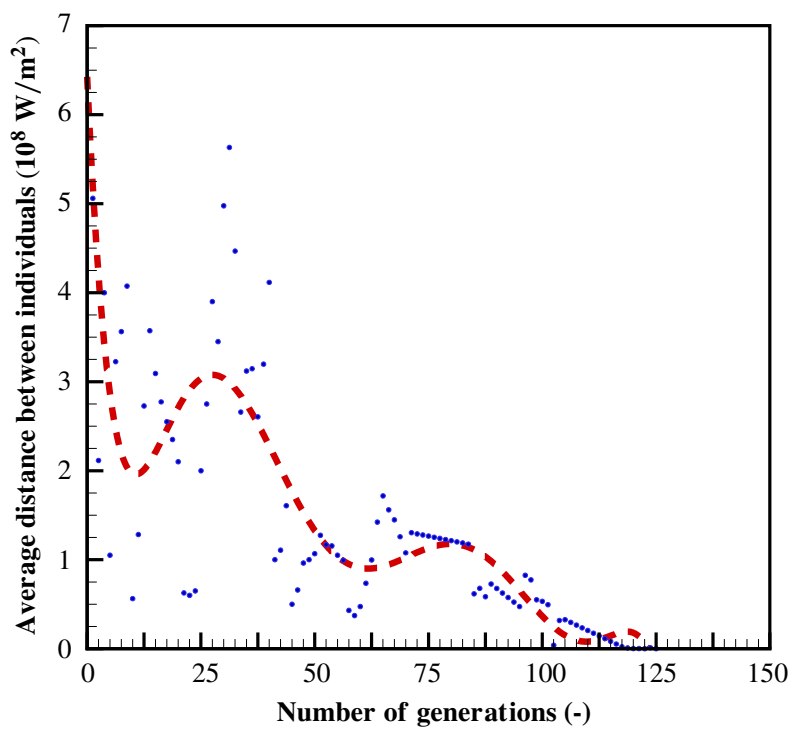

Figure 9: Convergence graph of the optimization process, measured in terms of the average distance between individuals (blue dots) versus the number of generations. A continuous curve is also fitted on the points (dashed red) to better visualize the convergence pattern.

required heating rates that should be added to the convergent part of the cascade for each case study, together with the blade's heating transfer area are also represented in the table.

In the next step, the characteristics of the flow with supersonic outlet under the optimal volumetric heating is investigated. First, the saturation temperature $T_{\text {sat }}$, i.e., the temperature at which the flow undergoes a phase change is considered. The saturation temperature is directly related to the flow pressure and experiences the same changes as the pressure by adding the volumetric heating to the flow. As

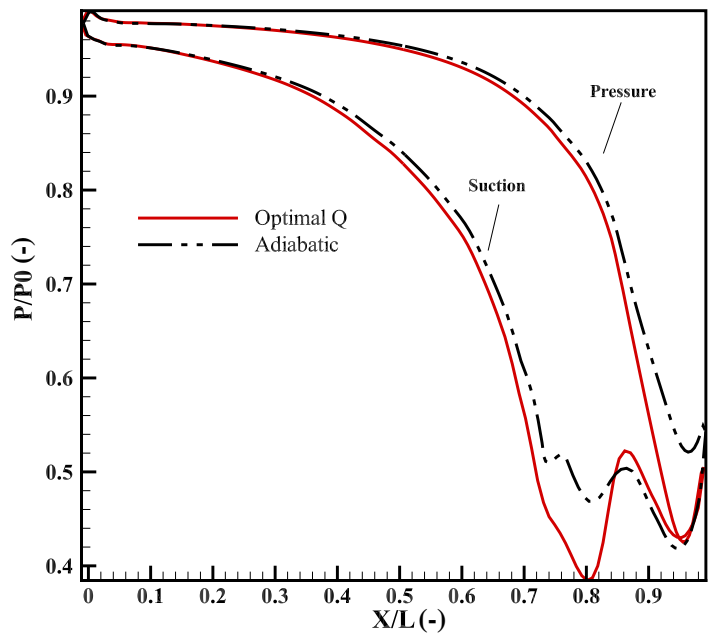

(a)

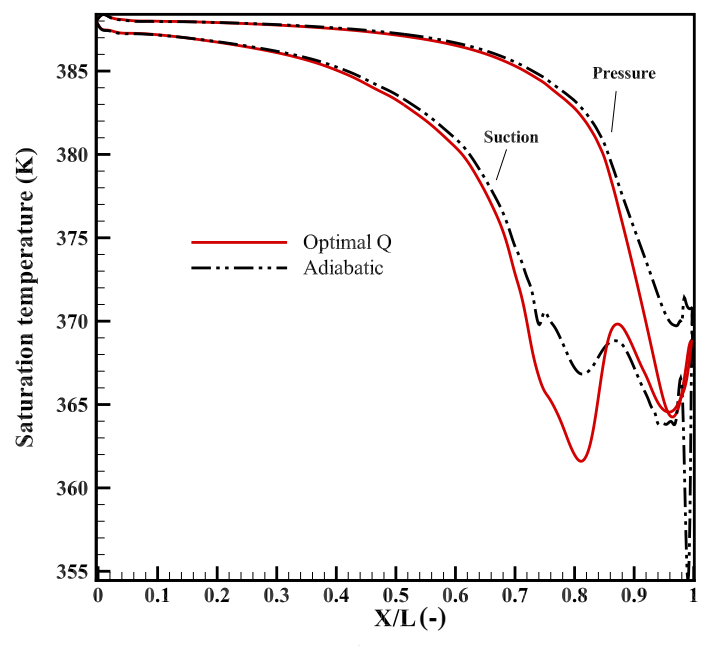

(b)

Figure 10: The pressure distribution (a) and saturation temperature (b) on the suction and pressure sides under the adiabatic and optimal heating cases. Note the smaller condensation sock and transformation of its location toward the passage outlet. 


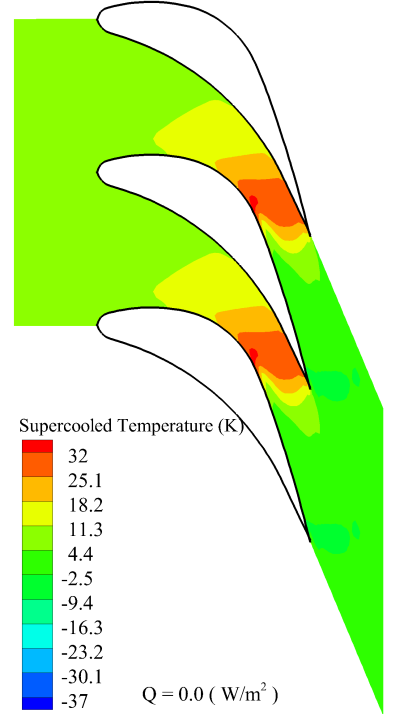

(a)

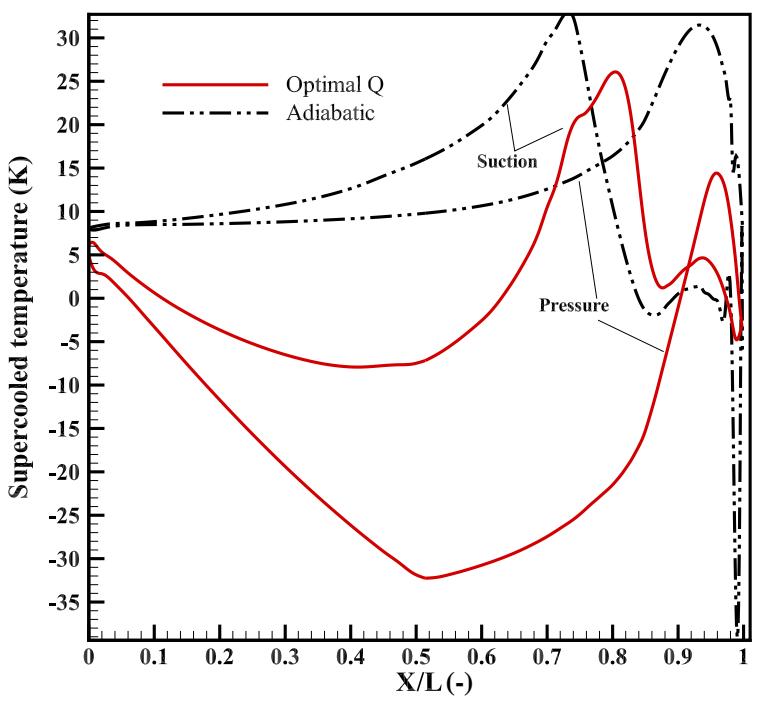

(c)

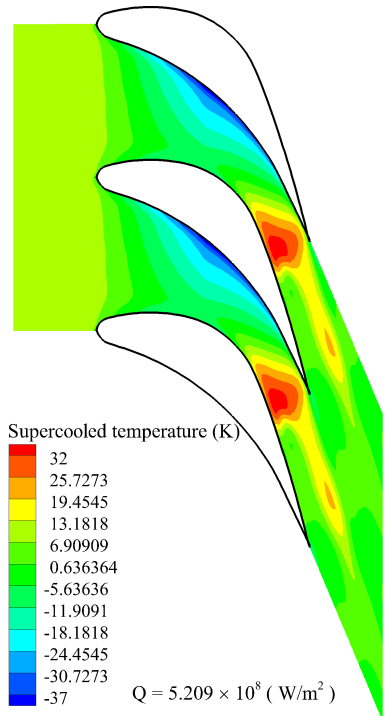

(b)

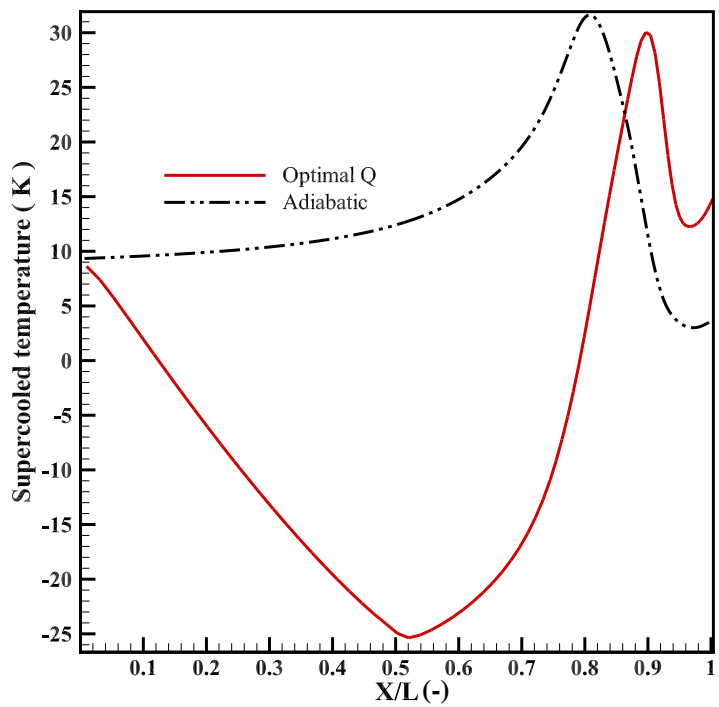

(d)

Figure 11: The supercooling temperature contours of the adiabatic and optimal cases (a,b), and the distribution of the supercooling temperature on the suction and pressure walls (c) and over the centerline of the flow passage (d).

shown in Figure 10a for the pressure, the steam flow reveals a very slight condensation shock under the optimal volumetric heating, which is almost the identical to the case of saturation temperature in Figure 10b. As it can be seen in the figure, compared to the adiabatic case, the saturation temperature observes a bigger decrease after the throat and near the suction and pressure sides.

The supercooling temperature is also dependent on the saturation temperature $T_{s a t}$ and the steam temperature $T_{v}$. As shown in Figure 10, applying the optimal volumetric heating to the flow leads to a larger drop in the pressure, resulting in a large decrease in the saturation temperature. Since the supercooling temperature is dependent on the difference between the static temperature of the steam and its saturation temperature, the large decrease of the sat- uration temperature under the optimal volumetric heating rate implies a large decrease of the supercooling temperature, which can be observed in Figure 11. As depicted in Figures $11 \mathrm{c}$ and $11 \mathrm{~d}$, the supercooling temperature significantly changes on the suction and pressure walls as well as the centerline. The graphs indicate the supercooling temperature is negative under the optimal volumetric heating case. According to the definition of the supercooling temperature, its negativity connotes that the flow changes into a superheated vapor preventing the condensation. It can be seen that under the optimal volumetric heating rate, the supercooling temperature reaches at lower maximums both on the walls and over the centerline. All the maximum values are also moved toward the downstream, resulting in a lower wetness in the flow through the cascade. 


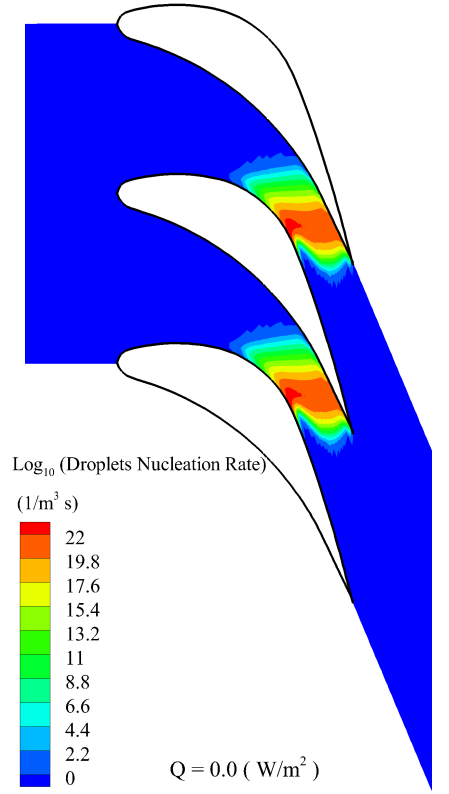

(a)

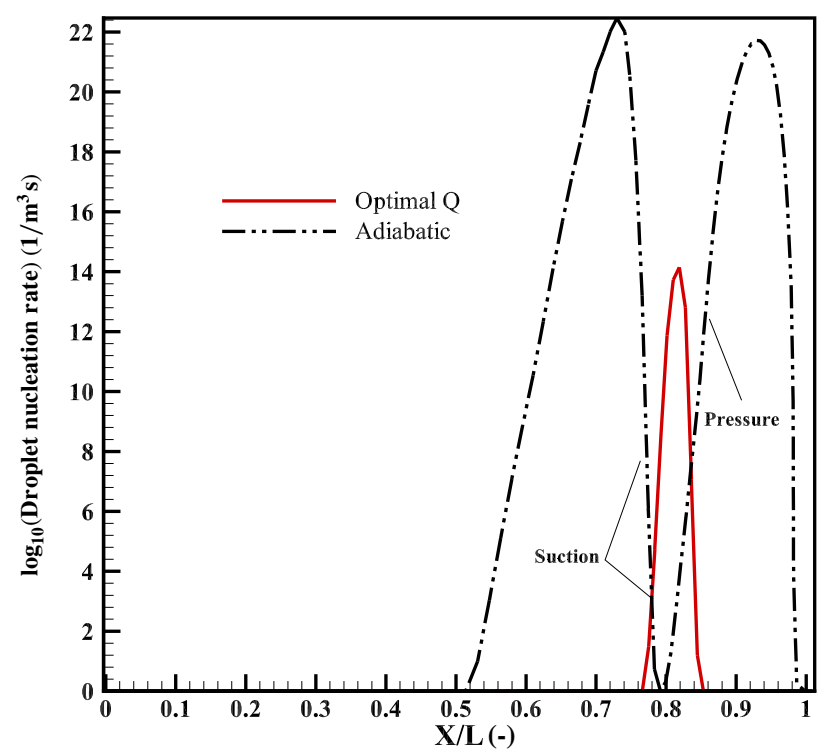

(c)

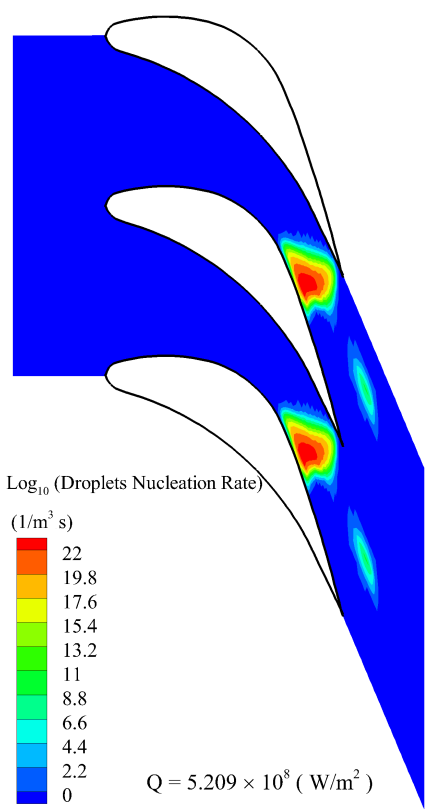

(b)

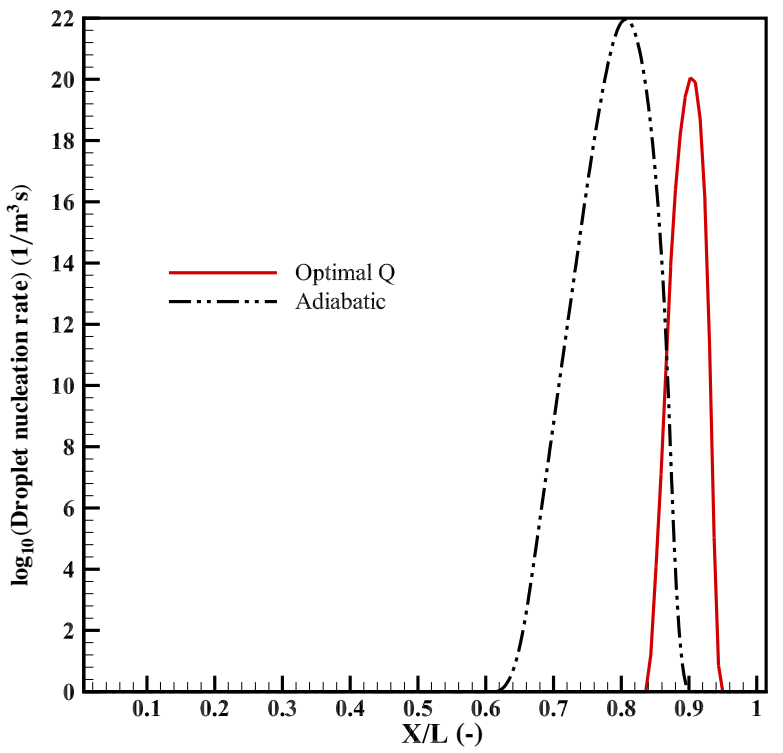

(d)

Figure 12: The contours of droplet nucleation rate $(I)$ for the adiabatic and optimal cases $(\mathrm{a}, \mathrm{b})$, and the distribution of the droplet nucleation rate on the suction and pressure walls (c) and over the centerline of the flow passage (d). Since the supercooling temperature is negative on the pressure side almost throughout the entire passage (see Figure 11c), the droplet nucleation rate on the pressure side under the optimal volumetric heating rate is negligible and not represented.

Figures $12 \mathrm{a}$ and $12 \mathrm{~b}$ show the contours of the droplet nucleation rate $(I)$ in both the adiabatic and optimal cases. In the adiabatic case, the droplet nucleation rate is higher at and after the throat, from the suction to the pressure sides. Interestingly, as shown in Figure 12c, in the optimal case, the droplet nucleation rate shows a lower maximum over the suction side that is observed closer to the outlet of the passage. The same trend is also observable over the centerline in Figure 12d. Moreover, the droplet nucleation rate is negligi- ble on the pressure side due to the fact that the supercooling temperature on the pressure side is negative almost throughout the entire passage (see Figure 11c), leading to a totally lower wetness fraction.

The wetness fraction as one of the most important characteristics of the two-phase wet steam flow is investigated and shows a remarkable improvement under the optimal volumetric heating rate. Figure $13 \mathrm{~b}$ illustrates the wetness fraction computed under $Q=5.21 \times 10^{8} \mathrm{~W} / \mathrm{m}^{2}$ for the super- 


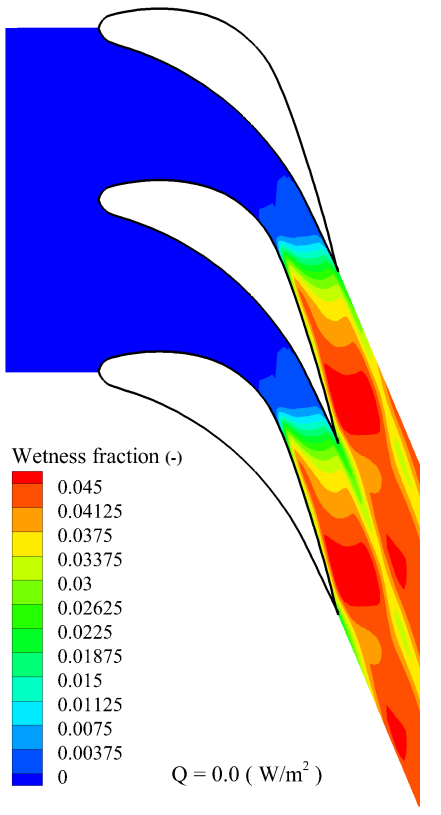

(a)

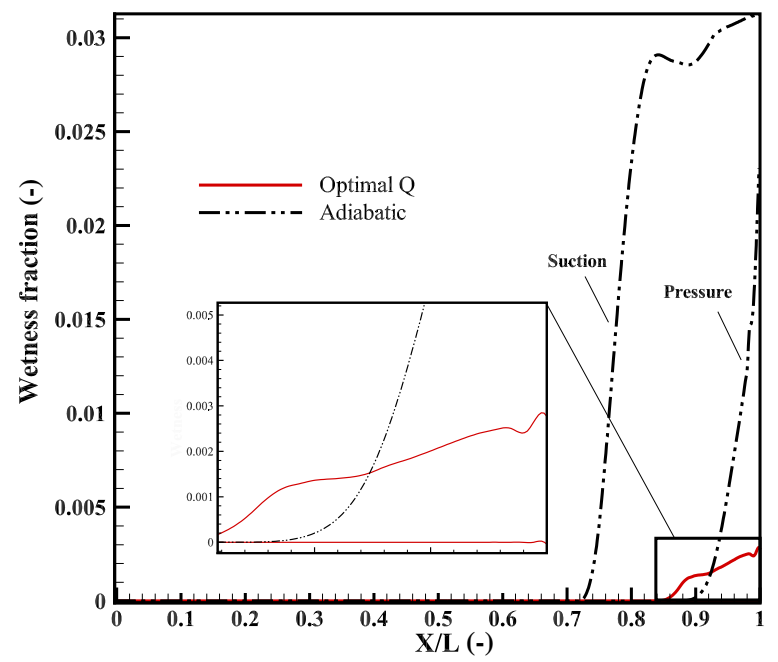

(c)

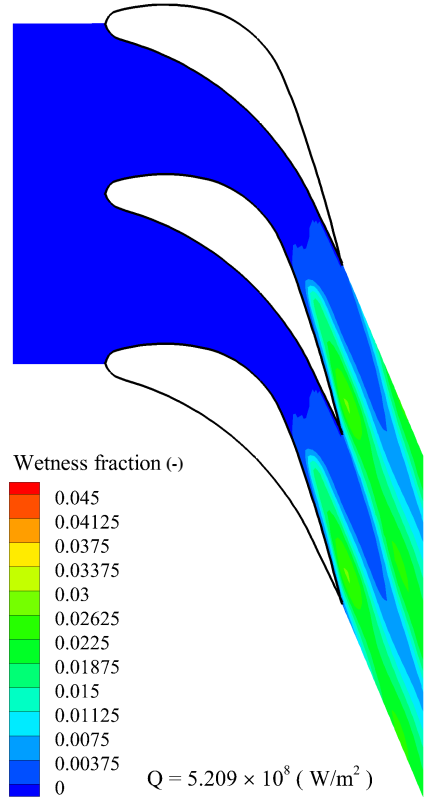

(b)

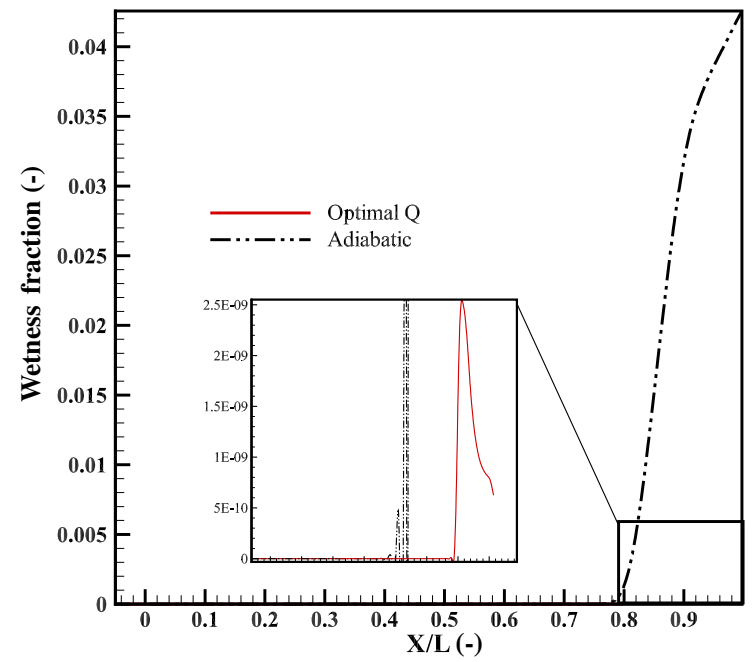

(d)

Figure 13: The contours of wetness fraction $(\beta)$ for the adiabatic and optimal cases $(a, b)$, and the distribution graphs of the wetness fraction on the suction and pressure walls (c) and over the centerline of the flow passage (d). Note that the wetness fraction is almost zero over the pressure wall.

sonic outlet case. Figure 13a again represents the adiabatic wetness contour for a better comparison. As demonstrated in Figure 13c, under the optimal $Q$, the wetness fraction is almost zero on the pressure side and has a very small value on the suction side and over the centerline (see Figure 13d) at the end of the passage.

Inasmuch as the wetness fraction and droplet nucleation rate are both reduced in the diverging part of the cascade under the optimal volumetric heating rate, the droplet average radius, $\bar{r}$, also demonstrates a decreasing trend under the optimal rate of $Q$. Figures 14a and 14b compares the contours of droplet average radius for the adiabatic and optimal cases. The adiabatic case is represented again for a better comparison. As indicated in Figures $14 \mathrm{c}$ and 14d, the droplet radius are significantly diminished on the suction and pressure sides as well as over the centerline. It can be inferred from these figures that the objective, DAR, that is obtained by the area integral of $\bar{r}$ at the passage outlet (i.e., at $X / L=1$ ) is well minimized by performing the proposed optimization process.

The next studied characteristic of the flow is the number of droplets per volume $(\eta)$. The second objective function 


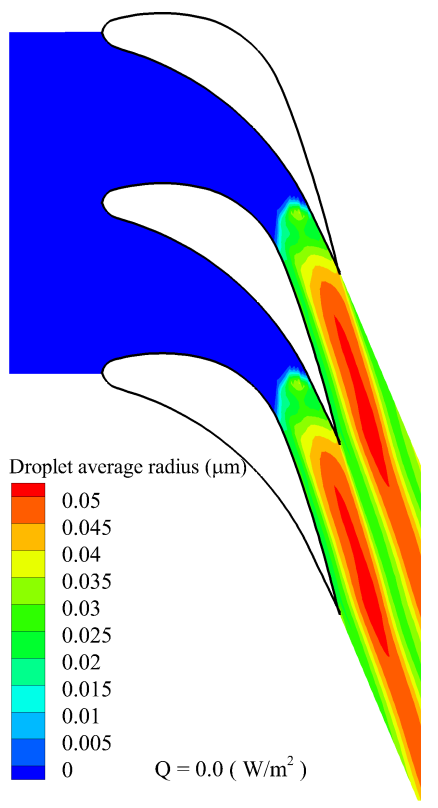

(a)

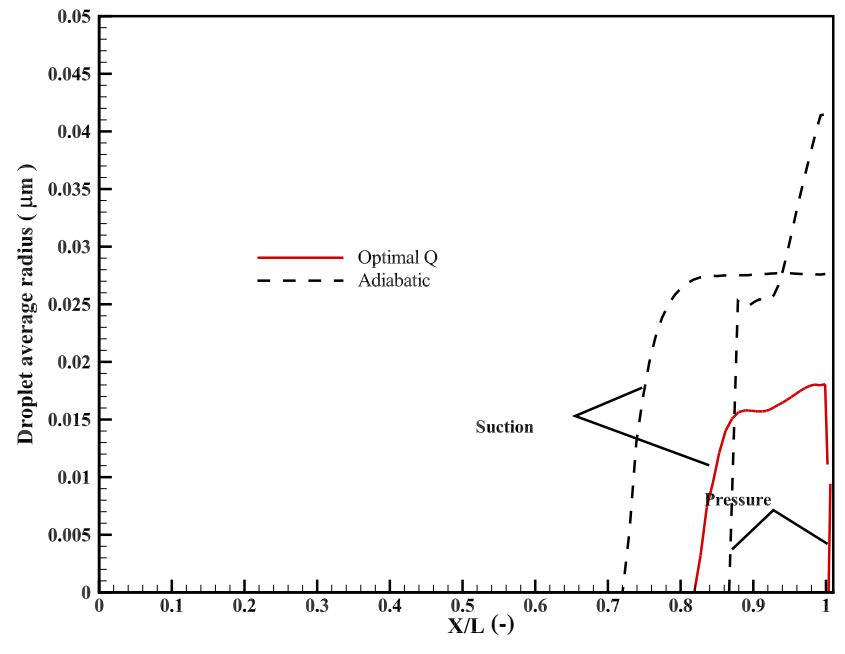

(c)

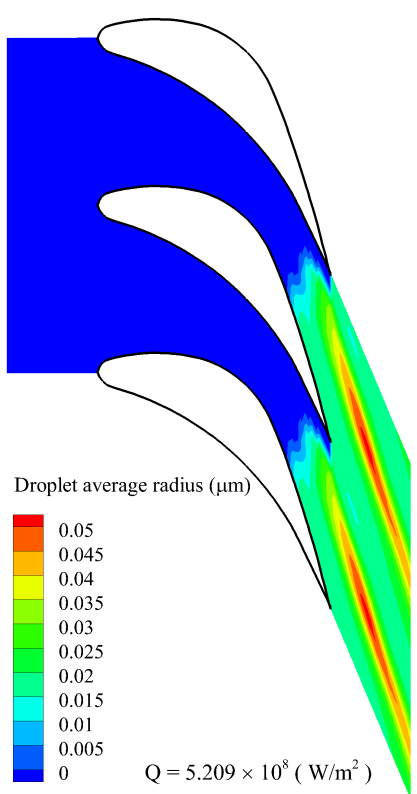

(b)

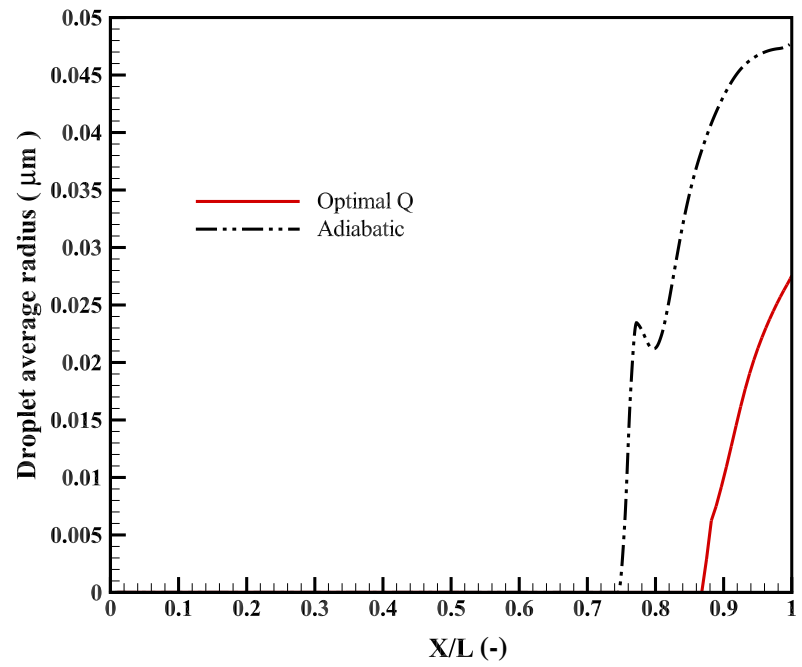

(d)

Figure 14: The contours of the droplet average radius $(\bar{r})$ for the adiabatic and optimal cases (a,b), and the distribution graphs of the droplet average radius on the suction and pressure walls (c) and over the centerline of the flow passage (d). Note that $\bar{r}$ is very small (almost zero) over the pressure wall, which is in a good agreement with the graphs of the droplet nucleation rate (Figure 12) and wetness fraction (Figure 13).

that is minimized in the presented research is the value of LND, obtained at the end of the passage using Eq. (20). More precisely, the number of droplets per volume over the flow area at the passage outlet is integrated in the similar manner as DAR. According to Figure 15, the number of droplets per volume decreases under the optimal volumetric heating rate. Additionally, the location at which the first droplets are constructed is also transformed toward the downstream. Referring to Figures $15 \mathrm{c}$ and $15 \mathrm{~d}$, the number of droplets on the pressure side shows a significant reduction, while it is not very well decreased on the suction side and over the centerline. However, considering that the average radius of droplets are very small and the wetness fraction is well reduced under the optimal heating rate (see Figures 13 and 14), one concludes that in spite of existence of droplets, their radius is extremely small, which results in minimizing the losses of the steam turbine.

Finally, the local entropy of the flow under the optimal volumetric heating rate is investigated. As already stated in Section 6 and also depicted in Figure 8, application of volumetric heating to the converging part of the cascade increases the local entropy of the flow compared to the adi- 


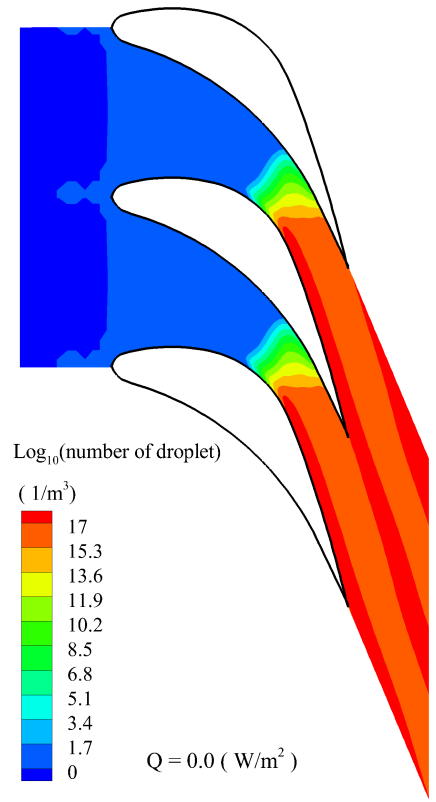

(a)

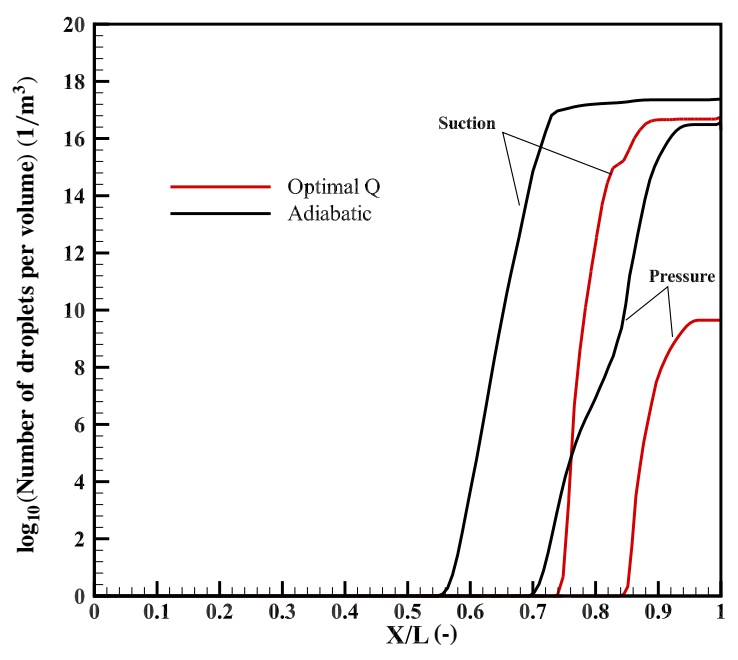

(c)

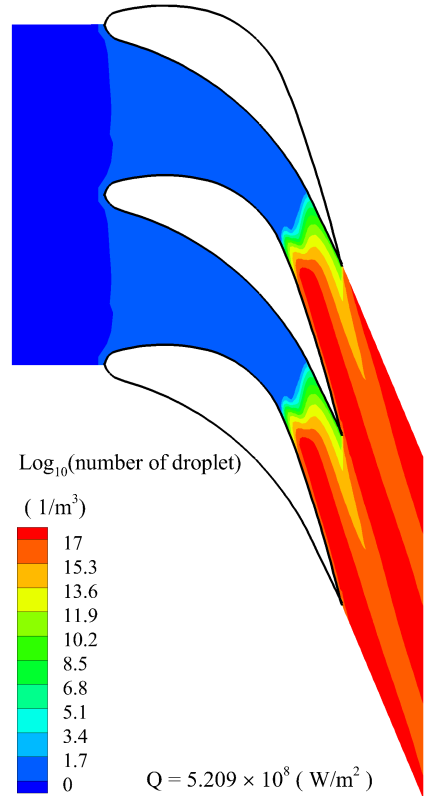

(b)

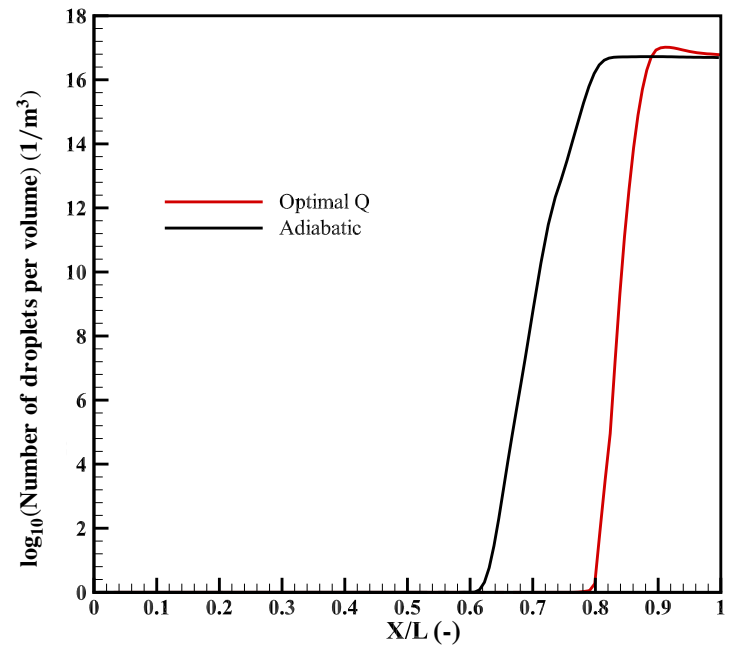

(d)

Figure 15: The contours of number of droplets per volume $(\eta)$ for the adiabatic and optimal cases (a,b), and the distribution graphs of $\eta$ on the suction and pressure walls (c) and over the centerline of the flow passage (d). Note that although droplets still exist under the optimal volumetric heating rate, their average radius is extremely small (see see Figure 14).

abatic case. The reason is the increase of the temperature of both liquid and vapor phases of the steam. The increase of the entropy is an undesirable effect of adding volumetric heating to the flow. Therefore, by defining ILE as an objective function that integrates the local entropy at the end of the passage, the best volumetric heating rate is found under which the local entropy of the flow increases in a reasonable manner while the wetness and the respective losses decrease. Figures 16a and 16b compare the entropy contours for the adiabatic and optimal cases. The graphs of entropy distribution on the suction and pressure sides and also over the centerline are demonstrated in Figures 16c and 16d. It should be noted that after the condensation is occurred, the entropy of the flow shows a decreasing trend since the lower entropy of the droplets reduces the total entropy of the mixture.

\section{Discussions}

Based on the results obtained during the course of this research, some explanatory remarks regarding the current case study are in order:

- The implementation of the Eulerian-Eulerian method facilitates the solution of equations in contrast to the Eulerian-Lagrangian approach since it does not require to determine the flow path from one cell to another in 


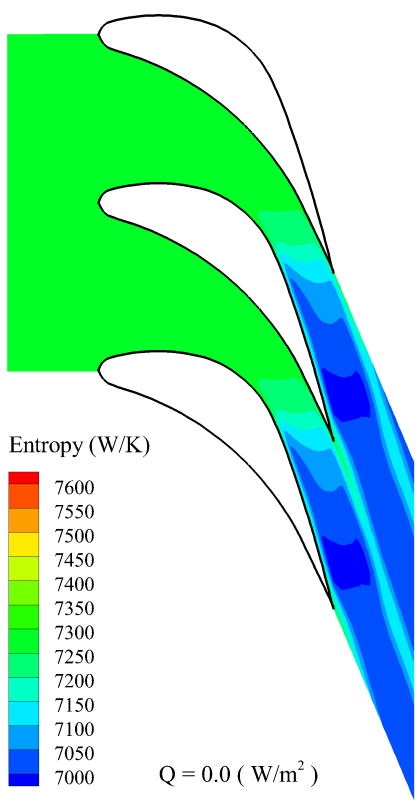

(a)

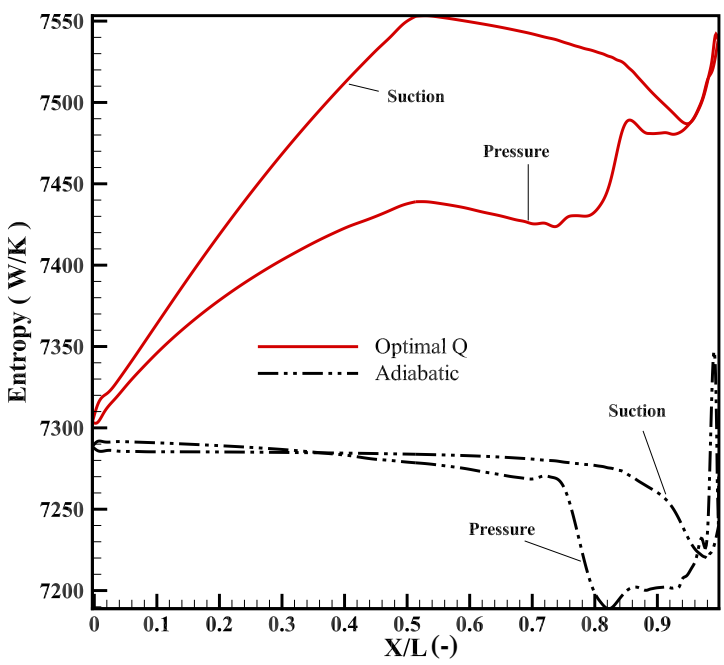

(c)

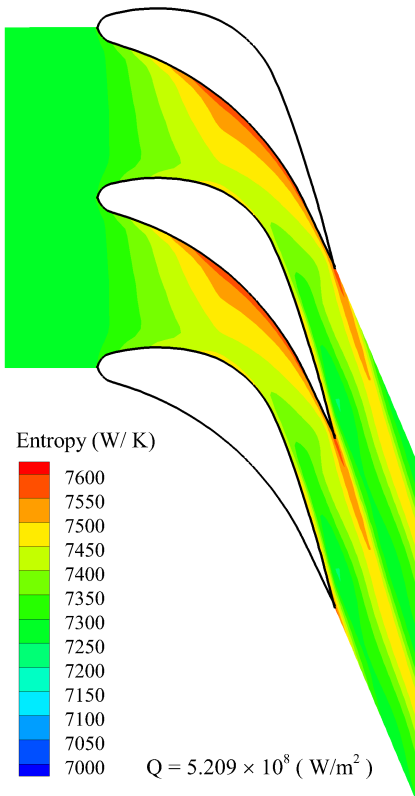

(b)

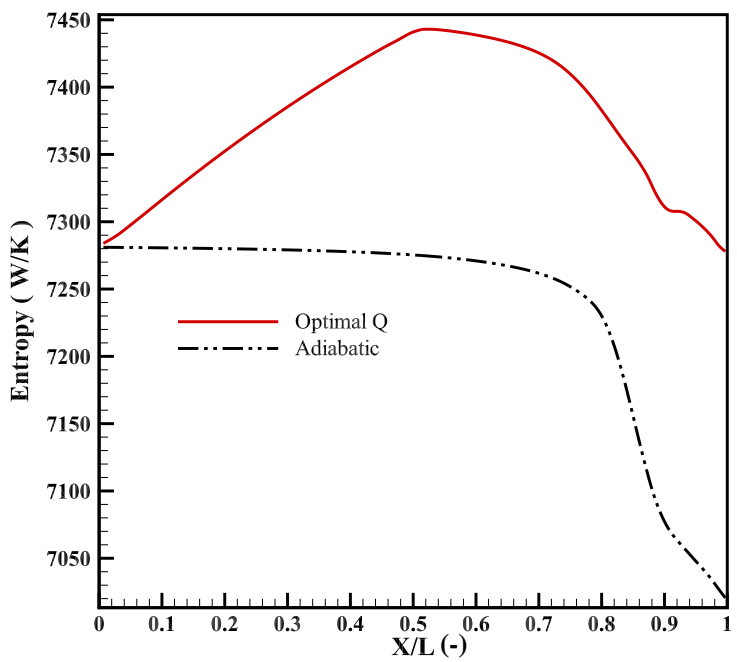

(d)

Figure 16: The contours of the local entropy of the steam flow for the adiabatic and optimal cases (a,b), and the entropy distribution graphs on the suction and pressure walls (c) and over the centerline of the flow passage (d).

the context of finite volume analysis. However, the disadvantage of the Eulerian-Eulerian method compared to the Eulerian-Lagrangian approach is that the integration of droplet growth in a cell is not performed along the flow line (i.e., actual droplet motion path), which may deteriorate the approximation of droplet radius.

- The SST $k-\omega$ turbulence model has a high requirement for wall treatment. Nevertheless, Taking into account the complexity of the simulation of two-phase two-dimensional turbulent flow through a curved geometry and also the iterative nature of the optimization process, considering a very fine grid near the walls entails higher computational costs. Moreover, as studied by Menter et al. [45] and the references therein, for complex industrial flows, obtaining low values of "dimensionless distance of node to wall" is an excessive requirement and cannot be satisfied for all walls in most occasions. Finally, the numerical results presented in the current research showed a good accuracy compared to well-established experiments, justifying the adequacy of the employed grid. 


\section{Conclusions}

In this research, the two-dimensional two-phase wet steam turbulent flow through stationary cascades of steam turbines is analyzed. In order to reduce the losses due to the persistent wetness, by means of applying the volumetric heating to the convergent section of the passage, the logarithm of number of droplet per volume (LND), the droplet average radius (DAR), and the integral of local entropy (ILE), measured at the end of the blade cascade, is minimized. For this purpose, a multiobjective optimization process is employed, where the volumetric heating rate is the design variable. To achieve this, the use of a blackbox optimization procedure is proposed through the automatic linking of the GA algorithm and the CFD code, in which the function evaluations are performed by means of CFD runs. Since increasing the volumetric heating leads to the reductions of DAR and LND and the increase of ILE, an optimal value for the volumetric heating rate can be obtained to reach the best performance of the steam turbine with a lower wetness in the flow and with a reasonable cost increase for the additional heating. Based on the results obtained for the model problem under two practical working conditions, the wetness (measured in terms of number and average radius of droplets) as well as the consequent losses at the last-stage turbine cascades can be reduced by adding the volumetric heating rates of $5.21 \times 10^{8}$ and $4.67 \times 10^{8} \mathrm{~W} / \mathrm{m}^{2}$ for supersonic and subsonic outlet cases, respectively. Adding these heating rates to the convergent part of the blades amount to the improvement of DAR by $45.7 \%$ and $57.5 \%$, and LND by $6.0 \%$ and $7.8 \%$ for respective cases.

As future work, it is proposed to find not only the optimal rate of volumetric heating, but also the optimal values of other influential parameters, e.g., the hot steam injection and blade geometry, to further improve the performance of the steam turbines.

\section{Acknowledgment}

The third author has been partially funded by the BCAM "Severo Ochoa" accreditation of excellence (SEV-20170718), the Basque Government, Spain, through the BERC 2018-2021 program, and two projects of the Spanish Ministry of Science and Innovation, "DEEPINVERSE" with reference PID2019-108111RB-I00 (FEDER/AEI), and "MACROPISTAS" with reference PID2019-104488RB-I00 (AEI/FEDER, UE). The authors would also like to thank the anonymous reviewers for their comments that helped to improve the paper.

\section{References}

[1] F. Bakhtar, M. Y. Zamri, J. M. Rodriguez-Lelis, A comparative study of treatment of two-dimensional two-phase flows of steam by a Runge-Kutta and by Denton's methods, Proceedings of the Institution of Mechanical Engineers, Part C: Journal of Mechanical Engineering Science 221 (6) (2007) 689-706. doi : 10.1243/0954406jmes477.

[2] L. Xu, J. Yuan, Online application oriented calculation of the exhaust steam wetness fraction of the low pressure cylinder in thermal power plant, Applied Thermal Engineering 76 (2015) 357-366. doi:10.1016/j. applthermaleng. 2014.11.020.

[3] W. Wróblewski, S. Dykas, Two-fluid model with droplet size distribution for condensing steam flows, Energy 106 (2016) 112-120. doi:10.1016/j. energy. 2016.03.052.

[4] Y. Tang, Z. Liu, Y. Li, H. Wu, X. Zhang, N. Yang, Visualization experimental study of the condensing flow regime in the transonic mixing process of desalination-oriented steam ejector, Energy Conversion and Management 197 (2019) 111849. doi:10.1016/j. enconman. 2019. 111849.

[5] S. Sinha, B. E. Wyslouzil, G. Wilemski, Modeling of $\mathrm{H}_{2} \mathrm{O} / \mathrm{D}_{2} \mathrm{O}$ condensation in supersonic nozzles, Aerosol Science and Technology 43 (1) (2009) 9-24. doi : 10.1080/02786820802441771.

[6] R. Hagmeijer, R. H. A. IJzermans, F. Put, Solution of the general dynamic equation along approximate fluid trajectories generated by the method of moments, Physics of Fluids 17 (5) (2005) 156-101. doi:10.1063/1.1921147.

[7] S. Dykas, M. Majkut, M. Strozik, K. Smołka, Experimental study of condensing steam flow in nozzles and linear blade cascade, International Journal of Heat and Mass Transfer 80 (2015) 50-57. doi: 10.1016/j.i jheatmasstransfer. 2014.09.010.

[8] S. Dykas, W. Wróblewski, Two-fluid model for prediction of wet steam transonic flow, International Journal of Heat and Mass Transfer 60 (2013) 88-94. doi:10.1016/j. i jheatmasstransfer. 2012.12.024.

[9] Y. Patel, G. Patel, T. Turunen-Saaresti, Influence of turbulence modelling on non-equilibrium condensing flows in nozzle and turbine cascade, International Journal of Heat and Mass Transfer 88 (2015) 165180. doi : 10.1016/j. i jheatmasstransfer. 2015.04.069.

[10] S. Senguttuvan, J.-C. Lee, Numerical study of wet-steam flow in Moore nozzles, Journal of Mechanical Science and Technology 33 (10) (2019) 4823-4830. doi : 10.1007/s12206-019-0923-8.

[11] F. Bakhtar, K. Zidi, Nucleation phenomena in flowing high-pressure steam: Experimental results, Proceedings of the Institution of Mechanical Engineers, Part A: Journal of Power Engineering 203 (3) (1989) 195-200. doi:10.1243/PIME_PROC_1989_203_027_02.

[12] F. Bakhtar, K. Zidi, Nucleation phenomena in flowing high-pressure steam part 2: Theoretical analysis, Proceedings of the Institution of Mechanical Engineers, Part A: Journal of Power and Energy 204 (4) (1990) 233-242. doi :10.1243/PIME_PROC_1990_204_032_02.

[13] A. H. Yousif, A. M. Al-Dabagh, R. C. Al-Zuhairy, Non-equilibrium spontaneous condensation in transonic steam flow, International Journal of Thermal Sciences 68 (3) (2013) $32-41$. doi:10.1016/j. ijthermalsci.2013.01.002.

[14] A. Gerber, M. Kerman, A pressure based Eulerian-Eulerian multiphase model for non-equilibrium condensation in transonic steam flow, International Journal of Heat and Mass Transfer 47 (10) (2004) 2217-2231. doi:10.1016/j. i jheatmasstransfer. 2003.11.017.

[15] B. Nikkhahi, M. Shams, M.Ziabasharhagh, A numerical investigation of two-phase steam flow around a 2-D turbine's rotor tip, International Communications in Heat and Mass Transfer 36 (6) (2009) 632-639. doi : 10.1016/j. appl thermaleng. 2016.04.134.

[16] M. R. Mahpeykar, A. R. Teymourtash, E. Amiri Rad, Reducing entropy generation by volumetric heat transfer in a supersonic two-phase steam flow in a laval nozzle, International Journal of Exergy 9 (1) (2011) 21-39. doi:10.1504/IJEX.2011.041428.

[17] E. Amiri Rad, M. R. Mahpeykar, A. R. Teymourtash, Evaluation of simultaneous effects of inlet stagnation pressure and heat transfer on condensing water-vapor flow in a supersonic laval nozzle, Scientia Iranica 20 (1) (2013) 141-151. doi:10.1016/j. scient.2012.12.009.

[18] M. A. F. Aliabadi, E. Lakzian, I. Khazaei, A. Jahangiri, A comprehensive investigation of finding the best location for hot steam injection into the wet steam turbine blade cascade, Energy 190 (2020) 116397. doi : 10.1016/j. energy. 2019.116397.

[19] M. Vatanmakan, E. Lakzian, M. R. Mahpeykar, Investigating the en- 
tropy generation in condensing steam flow in turbine blades with volumetric heating, Energy 147 (2018) 701-714. doi :10.1016/j . energy. 2018.01 .097$.

[20] R. Hosseini, E. Lakzian, Optimization volumetric heating in condensing steam flow by a novel method, Journal of Thermal Analysis and Calorimetry (2019) 1-13. doi : 10.1007/s10973-019-09001-1.

[21] H. Ding, Y. Li, E. Lakzian, C. Wen, C. Wang, Entropy generation and exergy destruction in condensing steam flow through turbine blade with surface roughness, Energy Conversion and Management 196 (2019) 1089-1104. doi :10.1016/j. enconman. 2019.06.066.

[22] A. Ebrahimi-Fizik, E. Lakzian, A. Hashemian, Entropy generation analysis of wet-steam flow with variation of expansion rate using NURBS-based meshing technique, International Journal of Heat and Mass Transfer 139 (2019) 399-411. doi:10.1016/j. ijheatmasstransfer. 2019.05.010.

[23] M. A. F. Aliabadi, E. Lakzian, A. Jahangiri, I. Khazaei, Numerical investigation of effects polydispersed droplets on the erosion rate and condensation loss in the wet steam flow in the turbine blade cascade, Applied Thermal Engineering 164 (2020) 114478. doi:10.1016/j. applthermaleng. 2019.114478.

[24] A. R. Teymourtash, J. A. Esfahani, S. M. Shaegh, The effects of rate of expansion and injection of water droplets on the entropy generation of nucleating steam flow in a laval nozzle, Heat and Mass Transfer 45 (9) (2009) 1185-1198. doi : 10.1007/s00231-009-0490-0.

[25] A. Ebrahimi-Fizik, E. Lakzian, A. Hashemian, Numerical investigation of wet inflow in steam turbine cascades using NURBSbased mesh generation method, International Communications in Heat and Mass Transfer 118 (2020) 104812. doi:10.1016/j. icheatmasstransfer. 2020.104812.

[26] D. Goldberg, Genetic Algorithms in Search, Optimization and Machine Learning, Addison-Wesley Professional, Reading, MA, 1989.

[27] S. J. Keisari, M. Shams, Shape optimization of nucleating wet-steam flow nozzle, Applied Thermal Engineering 103 (2016) 812-820. doi : 10.1016/j. appl thermaleng. 2016.04.134.

[28] M. S. Mirhoseini, M. Boroomand, Multi-objective optimization of hot steam injection variables to control wetness parameters of steam flow within nozzles, Energy 141 (2017) 1027-1037. doi:10.1016/j. energy. 2017.09.138.

[29] S. M. A. Noori Rahim Abadi, A. Ahmadpour, S. M. N. R. Abadi, J. P. Meyer, CFD-based shape optimization of steam turbine blade cascade in transonic two phase flows, Applied Thermal Engineering 112 (2017) 1575-1589. doi:10.1016/j. applthermaleng. 2016.10.058.

[30] M. A. Trigg, G. R. Tubby, A. G. Sheard, Automatic Genetic Optimization Approach to Two-Dimensional Blade Profile Design for Steam Turbines, Journal of Turbomachinery 121 (1) (1999) 11-17. doi : $10.1115 / 1.2841220$.

[31] R. G. Regis, C. A. Shoemaker, Constrained global optimization of expensive black box functions using radial basis functions, Journal of Global Optimization 31 (1) (2005) 153-171. doi:10.1007/ s10898-004-0570-0.

[32] K. K. Vu, C. D’Ambrosio, Y. Hamadi, L. Liberti, Surrogate-based methods for black-box optimization, International Transactions in Operational Research 24 (3) (2017) 393-424. doi:10.1111/itor. 12292.

[33] A. Altan, R. Hacioğlu, Model predictive control of three-axis gimbal system mounted on UAV for real-time target tracking under external disturbances, Mechanical Systems and Signal Processing 138 (2020) 106548. doi :10.1016/j. ymssp. 2019.106548.

[34] A. Hashemian, S. F. Hosseini, An integrated fitting and fairing approach for object reconstruction using smooth NURBS curves and surfaces, Computers \& Mathematics with Applications 76 (7) (2018) 1555-1575. doi:10.1016/j. camwa.2018.07.007.

[35] F. R. Menter, Two-equation eddy-viscosity turbulence models for engineering applications, AIAA Journal 32 (8) (1994) 1598-1605. doi : 10.2514/3.12149.

[36] H. Huang, T. Sun, G. Zhang, D. Li, H. Wei, Evaluation of a developed SST $k$ - $\omega$ turbulence model for the prediction of turbulent slot jet impingement heat transfer, International Journal of Heat and Mass Transfer 139 (2019) 700-712. doi:10.1016/j.ijheatmasstransfer.
2019.05 .058$.

[37] A. Novotny, H. Petzeltová, Weak solutions for the compressible navier-stokes equations: Existence, stability, and longtime behavior, in: Y. Giga, A. Novotny (Eds.), Handbook of Mathematical Analysis in Mechanics of Viscous Fluids, Springer International Publishing, New York, NY, 2017.

[38] X.-D. Wang, J.-L. Dong, T. Wang, J.-Y. Tu, Numerical analysis of spontaneously condensing phenomena in nozzle of steam-jet vacuum pump, Vacuum 86 (7) (2012) 861-866. doi:10.1016/j.vacuum. 2011. 02.016.

[39] M. R. Mahpeykar, E. Lakzian, E. Amirirad, Reduction of thermodynamic losses in a supersonic nucleating steam nozzle by spraying water droplets, Scientia Iranica 16 (3) (2009) 253-262. doi:http: //scientiairanica.sharif.edu/article_3218.html.

[40] F. Bakhtar, M. Ebrahimi, R. A. Webb, On the performance of a cascade of turbine rotor tip section blading in nucleating steam: Part 1: Surface pressure distributions, Proceedings of the Institution of Mechanical Engineers, Part C: Journal of Mechanical Engineering Science 209 (2) (1995) 115-124. doi:10.1243/pime_proc_1995_209_131_ 02.

[41] F. Bakhtar, J. B. Young, A. J. White, D. A. Simpson, Classical nucleation theory and its application to condensing steam flow calculations, Proceedings of the Institution of Mechanical Engineers, Part C: Journal of Mechanical Engineering Science 219 (12) (2005) 1315-1333. doi : $10.1243 / 095440605 \times 8379$.

[42] J. B. Young, An equation of state for steam for turbomachinery and other flow calculations, Journal of Engineering for Gas Turbines and Power 110 (1) (1988) 1-7. doi:10.1115/1.3240080.

[43] B. Sengupta, C. Bhattacharya, Investigation of energy loss on fractional deposition in last stages of condensing steam turbine due to blade shape and moisture droplet size, Journal of Engineering for Gas Turbines and Power 140 (7) (2018) 072601. doi: 10.1115/1.4038544.

[44] F. Bakhtar, M. R. Mahpeykar, K. K. Abbas, An investigation of nucleating flows of steam in a cascade of turbine blading-theoretical treatment, Journal of Fluids Engineering 117 (1) (1995) 138-144. doi: $10.1115 / 1.2816803$.

[45] F. R. Menter, M. Kuntz, R. Langtry, Ten years of industrial experience with the SST turbulence model, in: K. Hanjalić, Y. Nagano, M. J. Tummers (Eds.), Turbulence, Heat and Mass Transfer 4, Begell House, New York, NY, 2003. 